\title{
La transcripción del alfabeto líbico-bereber canario: el ejemplo de El Hierro
}

\section{The Alphabetic Transcription of Canarian Libyco-Berber Script: The Case of El Hierro}

\author{
Irma Mora Aguiar \\ Universidad de La Laguna \\ Cátedra Cultural de Estudios Bereberes \\ https:// orcid.org/0000-0002-6259-6685 \\ irmamora7@gmail.com
}

Recibido: 22/03/2021; Revisado: 26/04/2021; Aceptado: 10/05/2021

\begin{abstract}
Resumen
Se aborda la transcripción del alfabeto líbico-bereber canario desde una perspectiva de análisis morfofonológica. Para ello, se parte del corpus epigráfico herreño y se compara con el conjunto continental. A través de este estudio, se constata la presencia de múltiples morfemas del líbico de Numidia en las inscripciones herreñas. A su vez, se detectan rasgos lingüísticos de los dialectos bereberes meridionales, confirmándose el vínculo del alfabeto canario con la variedad presahariana, descendiente del líbico oficial númida. Finalmente, se advierten diferencias ortográficas entre el norte y el sur de la Isla que podrían reflejar variedades diatópicas, diacrónicas y diastráticas.
\end{abstract}

Palabras clave: Transcripción alfabética, análisis morfofonológico, líbico-bereber, Canarias, El Hierro.

\begin{abstract}
This study aims to transcribe the Canarian Libyco-Berber alphabet, employing a morpho-phonological analysis approach and comparing the corpus of inscriptions from the island of El Hierro with the continental one. The study demonstrates that the inscriptions from El Hierro contain multiple morphemes also present in the oldest Libyco-Berber alphabet from Numidia. In addition, the island inscriptions exhibit linguistic features of the Southern Berber dialects, confirming the link between Canarian and pre-Saharan alphabets. Finally, epigraphic analysis shows differences between the north and south of El Hierro. This orthographic disparity could signify diatopic, diachronic and sociocultural variation.
\end{abstract}

Key words: Alphabetic Transcription, Morpho-Phonological Analysis, Libyco-Berber, Canary Islands, El Hierro. 


\section{INTRODUCCIÓN}

Según ciertos lingüistas, como Ignace Gelb (1976 [1952]: 84) y Louis-Jean CALVET (1996: 222), cualquier escritura desconocida resulta más fácil de transcribir cuando se conoce la lengua que refleja. Tal fue el caso, por ejemplo, de la lineal B: una escritura silábica micénica que el doctor Michael Ventris y el filólogo John CHADWICK (1962 [1958]) acabaron descodificando tras concluir que representaba un dialecto arcaico del griego. Previamente, la arqueóloga Alice E. Kober había reconocido las marcas de género y otros morfemas flexivos que Ventris identificó con las desinencias casuales (СHADWICK, 1962 [1958]: 52). Este procedimiento minucioso ${ }^{1}$ ofreció mayor solidez a su hipótesis que las meras conjeturas que ofrecían algunos de sus predecesores.

También, la traducción de los antiguos textos egipcios se apoyó en el conocimiento de la lengua copta. ${ }^{2}$ Previamente, se habían descifrado sus grafías a partir de la piedra de Rosetta: una inscripción bilingüe greco-egipcia; cuyo texto egipcio fue redactado en dos variedades gráficas: jeroglífica y demótica. Las labores de transcripción de François CHAMPOLLION (1822) se iniciaron a partir del antropónimo regio reconocible en la versión griega (Ptolemaios). Así, el carácter conservador que posee la onomástica en las lenguas fue aprovechado por Champollion para establecer paralelismos entre ambos códigos.

El desciframiento del alfabeto líbico oriental o númida no distó mucho de los ejemplos expuestos. Su transliteración fue posible gracias a una estela bilingüe púnica-líbica: la inscripción de Aṭban. Al igual que sucedió con las escrituras egipcias, la transcripción de la númida conllevó décadas de estudio por parte de diferentes autores, entre los que destacó SAULCY (1843) por descodificar la mitad del alfabeto a mediados del siglo XIX. A comienzos del siglo XX, se produjo el hallazgo de una segunda inscripción bilingüe en la ciudad de Dougga: la dedicatoria a Masinisa, que favoreció la transliteración del resto del alfabeto (MARCY, 1936; СНАвот, 1939, 1940). En cuanto a la traducción de estas inscripciones bilingües y, en general, del conjunto númida, los epigrafistas se han sustentado en lenguas del phylum afroasiático, especialmente en el bereber, ya que el libio parece reflejar una de sus variedades diacrónicas (JudAs, 1863; HALÉvY, 1874; MARCY, 1936; ChABOT, 1940; RÖSsler, 1958; CHAKeR, 1985; GALAND, 2002; etc.).

Con respecto al alfabeto líbico-bereber canario, se ha observado cierta

1 «Dos son los métodos que pueden seguirse. Uno consiste en el análisis metódico, (...); el otro procede por conjeturas más o menos justificadas. La intuición inteligente debe, por supuesto, desempeñar un papel en el primer caso; pero existen grandes diferencias entre un desciframiento basado en un cuidadoso análisis interno y otro obtenido mediante el ensayo y el error. De este último puede obtenerse el resultado correcto, pero será necesario confirmarlo por aplicación al material virgen, ya que por su origen no tiene fuerza probatoria alguna. Es preciso asimismo un criterio seguro para discriminar entre lo que es probable o improbable que un texto contenga. De esta facultad carecían visiblemente quienes comprometieron su reputación con el método conjetural» (СHADWICK, 1962 [1958]: 41-42).

2 No obstante, los egiptólogos del siglo XIX cometieron errores de traducción al equiparar el copto al egipcio antiguo, siendo realmente dos estados de la lengua bien diferenciados (CERVELLó, 2016: 269270). 
homogeneidad (SPRINGER, 2017) y un mayor parecido con las inscripciones númidas (SPRINGER, 1994, 2001: 166-171). No obstante, la variedad canaria contiene una serie de grafemas característicos de otros alfabetos, que están ausentes en el líbico oriental (SPRINGER, 2019). Tal y como concluimos en nuestra tesis doctoral, esas similitudes con el alfabeto oriental de Dougga se explican porque este constituyó la norma que se extendió por el norte de África tras la reunificación de Numidia (162 y 111 a. n. e.). Obviamente, con el debilitamiento de la dinastía masilia, la escritura evolucionó, adaptándose a las distintas variedades geográficas y sociales, así como a las funciones y soportes empleados por sus usuarios. Ello parece explicar la presencia en Canarias de grafemas ajenos al corpus oriental. Aparentemente, estos caracteres pertenecen a una modalidad líbica meridional que se distribuyó a lo largo de la franja esteparia durante los primeros siglos de nuestra era y, más tarde, hacia al Sáhara central. ${ }^{3}$ Probablemente, la difusión de dicho alfabeto estuvo relacionada con la romanización, pues esta propició un aumento demográfico, el empuje poblacional hacia el sur y la dinamización del comercio caravanero (EuZENNAT, 1985: 170; BÉNABOU, 1976: 167-175; Gsell, 1927: V, 4; Lhote, 1975: 164, 1982: 58; Demougeot, 1960: 219; CAmps, 1978: 161). Así, a través de la célebre Ruta de los Chotts o de los Lagos Salados (Trousset, 1982), la escritura líbico-bereber acabaría arribando a las inmediaciones del río Guir, Tafilalt, valles del Sous y Draa. Estas regiones concentran las inscripciones más similares a las canarias, por lo que se deduce que la escritura llegaría a las Islas con sus primeros pobladores desde las costas meridionales del actual Marruecos a partir de los siglos II-III d. n. e. (MorA, 2021), periodo que coincide con la mayoría de las dataciones canarias más antiguas (VELASCO et al., 2020). Dada la probada líbico-berberofonía de los antiguos habitantes de las Islas (AcostA, 2017, 2019a) y los parecidos de la escritura líbico-bereber canaria con la númida, resulta tentador transcribir sus inscripciones recurriendo en exclusiva a esta modalidad alfabética. No obstante, como apuntaba CHADWICK (1962 [1958]: 41-42), este procedimiento basado en «el ensayo y el error» solo proporcionaría conjeturas de obligada demostración. Además, permanecerían sin transcribir aquellos grafemas ajenos a la norma númida, que tendrían que estudiarse necesariamente a partir de otros alfabetos líbico-bereberes.

\section{METODOLOGÍA}

Para el análisis del alfabeto canario, hemos seleccionado el corpus de la isla de El Hierro. Ello se debe a que sus 114 paneles suponen más de la mitad de los aproximadamente doscientos estimados por SPRINGER (e. p.) para el conjunto canario. Por lo tanto, se trata de una muestra bastante representativa del líbicobereber de las Islas. Obviamente, las conclusiones extraídas deben extrapolarse con cautela al resto del Archipiélago, ya que, como apuntábamos, se observa una

3 La inscripción líbico-bereber más antigua del Sáhara central es, de momento, la hallada sobre un bloque del monumento funerario de Abalessa (Tamanghaset, Argelia), cuyos restos arqueológicos datan de los siglos Iv-v d. n. e. (vid. CAMPs, 1978: 61). 
clara uniformidad alfabética, pero también ciertas diferencias en las frecuencias de algunos caracteres (SPRINGER, 2017).

El corpus herreño ha sido comparado con 1389 inscripciones norteafricanas pertenecientes a estelas y paneles de diversos alfabetos antiguos y medievales (líbico oriental, occidental, meridional y líbico-bereber de transición) distribuidos desde la franja septentrional norteafricana hasta el Sáhara occidental. ${ }^{4}$ Así pues, al igual que han hecho nuestros predecesores para las escrituras indescifradas o poco conocidas, consideramos que los ensayos de transcripción no pueden evadir el análisis interno, fundamentalmente porque no está demostrada la existencia de inscripciones bilingües en Canarias. ${ }^{5}$

En este análisis, nos hemos apoyado en el método que desarrolló RössLER (1958) para desentrañar la morfología del líbico oriental, seguido principalmente por CHAKer $(1985 a, 1988)$ y JONGELING $(1984,1994)$. Más tarde, El KHAYARI (2004) lo aplicó para interpretar el líbico occidental. Este análisis trata de localizar segmentos permutables y conmutables entre pares mínimos que comparten la misma raíz léxica. Cuando carecíamos de pares mínimos para identificar estos morfemas, hemos recurrido al principio del triliterismo de la raíz (Rössler, 1958: 108). Según este principio, aplicable a otras lenguas afroasiáticas, las raíces se constituyen originalmente por un máximo de tres consonantes. ${ }^{6}$ Por consiguiente, todo signo adicional debería de reflejar un morfema gramatical. Además de en la epigrafía herreña, este procedimiento ya se ha aplicado al estudio de su toponimia aborigen (AсоsтA, 2019a: 205).

\section{CORPUS ALFABÉTICO}

En este apartado analizamos los grafemas líbico-bereberes herreños, ordenándolos según su supuesto lugar de articulación. Estos se representan atendiendo a su posición en los renglones, mayoritariamente verticales y leídos de abajo hacia arriba. Asimismo, exponemos su comportamiento en los alfabetos estudiados, centrándonos en El Hierro con el fin de advertir su hipotético valor fonológico y, si lo tuviera, morfológico.

4 Hemos desarrollado este trabajo en nuestra tesis doctoral La contextualización arqueológica y epigráfica de las inscripciones líbico-bereberes de El Hierro, defendida en la Universidad de La Laguna en 2021.

5 En Lanzarote y Fuerteventura se han documentado inscripciones bialfabéticas líbico-bereberes y líbico-canarias. Por los parecidos formales de estas últimas, algunos autores (PICHLER, 2003; FARRUJiA et al., 2009; BELMONTE et al., 2019: 223; PERERA y JiméneZ, 2020) han concluido que se trata de escritura latina, llegando incluso, en ocasiones, a clasificarla como cursiva pompeyana. Además, sin respaldarse en ningún método solvente de transcripción, PERERA y JiMÉNEz (2020:3) han defendido la existencia de paneles que contenían «(...) las mismas voces con caracteres de los dos tipos de alfabeto documentados en Fuerteventura (líbico-bereber y líbico-latino)». A pesar de ello, ningún latinista ha concluido aún que se trate verdaderamente de este alfabeto (RAMíreZ, 2010). Tampoco se ha pronunciado académica y públicamente al respecto la comisión de especialistas (ninguno de ellos en escritura líbico-bereber) invitada al encuentro privado Las voces de las palabras escritas. Escritura líbico-bereber y líbico-canaria, celebrado en Lanzarote en octubre de 2017. Por lo tanto, consideramos aventurada la transcripción de un alfabeto poco conocido (el líbico-bereber) a partir de una grafía enigmática (la líbico-canaria). 6 Las raíces bilíteras y monolíteras se explican por el debilitamiento y la consecuente vocalización de los radicales correspondientes a semiconsonantes y consonantes posteriores (PRASSE, 1972: I-III, 104106). 


\subsection{Orden labial}

\section{El grafema $\bigcup$}

Se trata de un alógrafo del signo original X (Álvarez, 1964: figura 54; GALAND, 1976: 76; SPRINGER 2001: 169), que en el alfabeto líbico oriental representó el fonema */f/. Esta variante cuadrangular $(\forall)$ o redondeada $(\forall)$ es común en las inscripciones canarias realizadas mediante piqueteado. Igualmente, se documenta en algunos yacimientos ${ }^{7}$ de Draa-Tafilalt (Marruecos) y de Río de Oro-La Güera (Sáhara occidental) que contienen inscripciones líbico-bereberes medievales o de transición, lo que sugiere que era una variante relativamente tardía.

$\mathrm{Al}$ igual que en los alfabetos norteafricanos, en El Hierro el uso de $\forall$ fue escaso (2,19\% del corpus) y no se constata una pauta indicativa de su función morfológica. Debido a este comportamiento y a que la /f/ carece de función gramatical $^{8}$ en las lenguas líbico-bereberes, resulta verosímil que plasmara el mismo valor fonológico en las inscripciones herreñas. ${ }^{9}$ Por lo tanto, descartamos que anotase el fonema */g/, como sucede en el tifinagh de Ahaggar (Argelia), ya que, además, como se verá en el apartado 3.3, esta velar se representó mediante otro signo.

\section{El grafema $\odot$}

Tampoco es una letra especialmente frecuente en el corpus herreño $(2,08 \%)$ ni se observa ninguna función morfológica para ella. Tanto en el líbico oriental como en el occidental, representó el fonema */b/ (CHABOT, 1940: v; KHAYARI, 2004: 95) y, si bien carecía de valor gramatical, su presencia era elevada debido al uso de la fórmula BNS 'su estela, su lápida'. Como la escritura se empleó mayoritariamente en Canarias sobre soportes rupestres ajenos a los usos funerarios, es predecible la ausencia de esta fórmula. Igualmente, la frase 'su lápida' no sería aplicable para el chajasco de la necrópolis del Hoyo de Los Muertos (Guarazoca, Valverde), ya que se trata de un tablón de madera.

En definitiva, es más verosímil que el signo $\odot$ representase la */b/, como en los alfabetos líbicos, que la */s/, como en los tuaregs ${ }^{10}$ (vid. Aghali-ZaKara y Drouin, 2007: 28). De no ser así, observaríamos un comportamiento diferente para este grafema (i.e., frecuencia más elevada, combinación con otros caracteres, etc.), puesto que la consonante /s/ desempeña diversas funciones morfológicas en las lenguas líbico-bereberes, tal y como expondremos más adelante.

7 Hajart, Wiggane, Foum Chenna (Rodrigue y Pichler, 2007), Laghchiwat (Ewague, 2016), Monolito de Gleibat Ensur y Leyuad (GALAND, 1973a).

$8 \mathrm{El}$ valor gramatical de esta consonante se restringe actualmente a las preposiciones bereberes af(ella) y eyaf'sobre' (vid. NAÏT ZERRAD, 2011).

9 Es probable que, en cierto estado de la lengua aborigen herreña, este grafema se realizara *[p], ya que así se conserva en la toponimia herreña de origen bereber, según ACOSTA (2019a: 230).

10 En los alfabetos tifinagh parece haberse producido una confusión entre los valores de la letras líbicas $\odot(* / b /$ en líbico y /s/ en tuareg) y $\Phi(* / s /$ en líbico y /b/ en tuareg), seguramente, motivada por sus similitudes gráficas. 


\subsection{Orden dental}

El grafema +

Es habitual en el corpus herreño (4,92 \%) y parece ejercer varias funciones gramaticales advertidas en el conjunto norteafricano. A esto hay que añadir que, tanto en los alfabetos líbicos antiguos como en los tuaregs actuales, representó el fonema */t/ (Снавот, 1940: v; Galand, 1966: 21; Aghali-ZaKara y Drouin, 2007: 28), por lo que resulta especialmente verosímil que en Canarias poseyera el mismo valor.

La *t de El Hierro parece haber representado mayormente dos morfemas característicos que marcan el género femenino en las lenguas líbico-bereberes: el prefijo verbonominal $(t-)$ y el circunfijo singular $(t-\ldots-t)$.

Con respecto al prefijo verbonominal $(t-)$, hemos hallado dos pares mínimos que demostrarían su existencia. Así, observamos que la supuesta raíz ${ }^{*} R N$ (La Cueva de Las Chivas 1.2 y Arenas Blancas 1.1) lleva prefijada esta * $t$ (*TRN) en el panel 1.1 de la Cueva del Agua. Además, la *t parece permutar con la desinencia masculina de $3 .^{\mathrm{a}}$ persona singular $\left({ }^{*} \mathrm{YRN}\right)$ en la inscripción 1.1 del Barranco del Cuervo. Asimismo, hallamos la conmutación de *t en la supuesta raíz *FM: *TFM (Barranco del Cuervo 9.5B) frente a * FM(-N) (La Candia 1.2).

El circunfijo singular $(t-\ldots-t)$ es una marca nominal líbico-bereber que parece haberse inscrito en las secuencias *TDKT (La Caleta 5.5) y *TKNT (Hoyo Blanco 1.2). Sin embargo, no contamos con pares mínimos que lo confirmen, ni tampoco podemos recurrir al triliterismo de la raíz para establecer tal valor. No obstante, en bereber, la / $t$ / muy rara vez tiene un valor de tercer radical, por lo que es bastante probable que se trate del sufijo nominal femenino.

\section{El grafema つ}

Es otro de los caracteres que comparte su valor */d/ en los alfabetos líbicos y en los tifinagh de Ghat (Libia) y Ahaggar (Argelia) (GALAND, 1966: 32; KHAYARI, 2004: 95-97; Aghali-Zakara y Drouin, 2007: 28). Tanto en las inscripciones norteafricanas como en las herreñas (donde suma el 3,28 \% del corpus) parece representar radicales léxicos. Además, tuvo un empleo reducido como conjunción copulativa, sobre todo en las estelas oficiales de Dougga, donde se enumeran diversos personajes. También en El Hierro pudo haberse usado como tal, pues se sitúa entre dos líneas (*SMS y *ML) de la inscripción 1.1 de El Tejal. Asimismo, la encontramos prefijada en la tercera línea desde la izquierda en el panel 1.4 de La Cueva de Don Gabino ( $\left.{ }^{*} \mathrm{DWHB}\right)$. Quizá, esta palabra estaba constituida por la conjunción y una raíz trilítera, o bien por un patronímico: *w $\mathrm{Hb}$ ¿'el hijo de $\mathrm{Hb}^{\prime}$ ? 
El grafema

Se trata de uno de los signos más complejos del corpus herreño (4,70\%), ya que se comporta de manera diferente a su equivalente númida $(* / \delta /)$. En efecto, en El Hierro, este grafema suele escribirse a final de palabra: un patrón que también observamos en Gran Canaria, ${ }^{11}$ Lanzarote, ${ }^{12}$ Fuerteventura ${ }^{13}$ y en algunas inscripciones rupestres de La Cabilia ${ }^{14}$ (Argelia) y de Draa-Tafilalt. ${ }^{15}$ Por lo tanto, probablemente $\amalg$ representó un morfema. Dado que la $/ \mathrm{J} /$ es poco productiva, teniendo únicamente una función expresiva en bereber (KossmanN, 1999: 2019; NAÏT-ZERRAD, 2002a: 356), habría que descartar que plasmara esta consonante. Seguramente, la clave para descifrar este signo esté en otro gráficamente próximo perteneciente a la norma oficial númida: la *t de Dougga $(\epsilon)$. Dicha letra podría ser su antecesora, ya que se observa una progresiva pérdida de su apéndice lateral, ${ }^{16}$ que le hace adquirir una forma parecida a $\ni$ (lectura horizontal sinistrorsa). Asimismo, este grafema representa la dental faringalizada en los actuales alfabetos tifinagh de Ahaggar y Ghat (vid. Aghali-ZaKara y Drouin, 2007: 28), de manera que parece muy probable que también descienda de la * $t$ de Dougga.

Su función morfológica se confirma a partir del triliterismo de la raíz, ya que encontramos la letra $\amalg$ sufijada a series triconsonánticas en La Candia 1.3 $\left({ }^{*} \mathrm{MNRT}\right)^{17}$ y 1.4 ( $\left.{ }^{*} \mathrm{NTTST}\right)$. Además, también la hallamos al final de las palabras *YZNKT (La Candia 1.4) y *WDDMT (La Caleta 5.2), que aparentemente están formadas por un prefijo $\left({ }^{*} y-\mathrm{y}{ }^{*} w-\right.$, respectivamente), una raíz trilítera y la supuesta ${ }^{*} t$.

En principio, sorprende que esta consonante correspondiera a un morfema, siendo más habitual esta función para su correlato no faringalizado. Quizá, la explicación radique en una supuesta realización $\left[\mathrm{t}^{\mathrm{f}}\right] \mathrm{de} / \mathrm{t} /$ en posición final. Un comportamiento similar se ha documentado en algunos dialectos cenetes meridionales actuales donde se faringaliza tanto la $t$ final como la inicial. Concretamente, en las regiones de Matmata (Gabes, Túnez) (Provotelle, 1911: 12) y, Touat y Gourara (Adrar, Argelia) (BASSET, 1885: 388-392). Consideramos esclarecedor que estas hablas se sitúen en los extremos del área de expansión

11 Durante la primera fase dedicada a Gran Canaria del Inventario de Inscripciones alfabéticas (proyecto dirigido por la Dra. Renata Springer en 2014), observamos este comportamiento en los siguientes paneles: Montaña de Birbique 1.1, Barranquillo del Cardón 1.1, Barranco del Roque 1.3, Roque de Cuevas del Rey 1.1, Lomo de las Tablas 1.1. Además, este patrón se repite en el Barranco de la Angostura, la Necrópolis de Arteara, el Barranco de Balos, Bandama y la Hoya de Toledo (vid. C.H.E.C., 1988; GarCía Navarro et al., 2004; Cuenca, 1996; Springer, 1996; Rodrigue y Pichler, 2007; Martín et al.,2008).

12 Concretamente, se inscribió en la Peña de Luis Cabrera, el Barranco de las Piletas, la Peña Juan del Hierro, Femés, Montaña Ortiz, (vid. Ulbrich, 1996; Rodrigue y Pichler, 2007).

13 Este signo se halla en posición final en el Morro de la Montaña Blanca y en el Morro de la Galera (vid. RODRIGUe y PICHLER, 2007).

14 Ifigha, Falaise de Roui y Azrou Bourzou (vid. SPRINGER, 1994: 215-235).

15 El Ghoula 2.3 y Rehris 2.5 (vid. Rodrigue y Pichler, 2007).

16 Contamos con dos ejemplos ilustrativos en las estelas de la Torre oeste y del Monumento de los nichos, recientemente descubiertas (vid. GHAKI, 2000: 1662, 2011: 5).

17 No obstante, la * $m$ inicial podría corresponder también al prefijo de nomen agentis. 
del antiguo alfabeto líbico meridional, variedad que seguramente se implantó en Canarias (MorA, 2021: 55). Igualmente, Acosta (2019a: 231) ha contemplado la posibilidad de que a la Isla arribara un habla cenete meridional.

\subsection{Orden alveolar}

El grafema $\ominus$

Se trata del alógrafo de la * s/ númida más habitual en El Hierro, resultante de la evolución de la forma original $\mathbb{Z}$. Esta última variante está también presente en la Isla, especialmente en las inscripciones realizadas mediante incisión. Ambas formas ascienden al 6,56\%: un porcentaje elevado que coincideconla productividad de la /s/ en las lenguas líbico-bereberes. De hecho, en las inscripciones herreñas distinguimos algunos morfemas con */s / característicos de la onomástica líbica, que han sido estudiados por numerosos autores (LETOURnEUX, 1878; СНАBOT, 1940; FÉVRIER, 1956; PrASSE, 1974; JONGELING, 1984; CHAKER, 1985a). Nos referimos al prefijo de nomen instrumenti, de causativo y factitivo (s-), así como a los pronombres enclíticos oblicuos de $3 .^{a}$ persona $(-s,-s n)$.

El prefijo de nomen instrumenti (s-) se suele encontrar adherido al de nomen agentis $(m-)$, formando el prefijo adjetivador denominal * $m s-$ (GALAND-PERNET y GALAND, 1995), que es especialmente habitual en la antroponimia númida (СНАвот, 1940: хIX) y aún lo conserva el habla tuareg de Mali (HeAtH, 2005: 552). Aparentemente, el prefijo adjetivador se empleó también en El Hierro, tal y como se deduce de su conmutación en los siguientes pares mínimos: *YN (El Tejal 1.2 y Barranco de Tejeleita 2.6 B) frente a *MSYN (Barranco de Tejeleita 2.6) y *WRN (Barranco del Cuervo 8.2) frente a ${ }^{*} \operatorname{MSWRN}_{1}$ (La Cueva de Don Gabino 1.2 G).

Los pronombres enclíticos oblicuos de $3 .^{\text {a }}$ persona $(-s,-s n)$ son frecuentes en el corpus líbico oriental y poseían dos funciones descritas por diversos especialistas (RÖssler, 1958: 112; Jongeling, 1984: 89; CHAKeR, 1985a: 487-488, 492-493). En primer lugar, la de adjetivo posesivo, cuando acompañaban a sustantivos, como se observa claramente en la fórmula funeraria númida bn-s 'su estela' (LETOURNEUX, 1878: 71). En cambio, ejercía la función de complemento indirecto cuando va acompañado de verbos, como, por ejemplo, señalaba CHAKER (1985a: 492) para el antropónimo YZGGSN (RIL ${ }^{18}$ 1109): "Y-ZGG (a)sen, de *ZGG (?)+(a)sen "a ellos" $\rightarrow$ "Él les..."».

En El Hierro se documenta la forma plural del pronombre oblicuo de 3. ${ }^{a}$ persona en las siguientes líneas: *NŠHSN (Barranco de Tejeleita 2.3), *YDRSN (Barranco del Cuervo 7.1), *TTTṬN (La Cueva de Don Gabino 1.1) y *ŠG SN (La Caleta 2.3 y 3.2). En los tres primeros ejemplos se segmenta el pronombre -sn a partir del principio del triliterismo de la raíz, aunque la ${ }^{*} n$ - y la * $y$ - iniciales podrían corresponder, respectivamente, a las desinencias verbales de 1 . $^{\mathrm{a}}$ persona

18 La sigla RIL hace referencia al Recueil des Inscriptions Libyques de CHAвот (1940), que contiene el corpus más amplio de estelas epigráficas líbicas. 
del plural y $3 .^{\text {a }}$ del masculino singular. Por consiguiente, el pronombre oblicuo equivaldría al complemento indirecto en estos casos. En cambio, la línea *TTTTSN parece formada por un sustantivo acompañado del posesivo, a saber: *titt (a)sen ¿'su (de ellos) ojo, su fuente' ? $^{19}$ Por último, observamos que los propios autores de la inscripción segmentaron con un punto el pronombre oblicuo del supuesto sustantivo en *ŠG SN: 'su (de ellos) šg'.

\section{El grafema $\mathrm{H}$}

Aparentemente, anotaba la */ $\mathrm{z}^{\varsigma}$ / en el líbico oriental (Снавот, 1940: V; cf. KossmanN, 2020: 877). No obstante, pudo haber plasmado la */z/ en el occidental y en el meridional para evitar confusiones con la ${ }^{*} n$ tras su rotación. ${ }^{20}$ Esta idea se apoya también en los alógrafos tuaregs de $z(\neq, \nvdash, \nVdash, \#)$, que resultan de la evolución o la duplicación de I.

Igualmente, el signo $H$ pudo plasmar el fonema */z/ en el líbico-bereber herreño, dado que este grafema parece descender del líbico meridional y, al igual que sucede en el vecino continente, de su análisis tampoco se infiere ninguna función morfológica. A pesar de ello, poseyó un uso más elevado (3,17 \%) que en otras regiones norteafricanas, probablemente debido al léxico empleado, o bien a aspectos fónicos como la sonorización de $s$ - en posición intervocálica o ante consonantes sonoras.

\section{El grafema $\top$}

Es un signo escaso en las inscripciones continentales, ya que parece haber plasmado la sibilante faringalizada $* / \mathrm{s}^{\uparrow} /$ : un fonema poco productivo en las lenguas líbico-bereberes. Igualmente, es minoritario en El Hierro $(0,77 \%)$, por lo que sería admisible que compartiera el mismo valor fonológico.

\subsection{Orden palatal}

\section{El grafemau}

Se trata del alógrafo más habitual, aunque también se documenta su forma original $w$ (con valor * $/ \int /$ en Dougga) en las inscripciones incisas herreñas, así como su variante diacrónica tardía $\Omega \Omega^{21}$ en algunas piqueteadas. Todos los

19 El sustantivo pan-bereber tițt designa 'ojo' y por extensión, 'fuente' (HADDADOU, 2006: 221).

$20 \mathrm{La}{ }^{*} n$ y la ${ }^{*} z$ númidas se representan, respectivamente, a través de una barra vertical y horizontal. No obstante, en el líbico occidental (GALAND, 1966: 25) y en el meridional parece abandonarse esta regla ortográfica, teniendo que adoptar una forma diferente para la */z/ (MORA, 2021).

21 Esta variante resultó del alargamiento de $\boldsymbol{\sim}_{\mathrm{y}}$ es aparentemente posterior a la forma original ${ }^{\text {}}$. Así mismo, se ha documento un alógrafo más tardío en Foum Chenna, generado tras el estiramiento de 几 . Las inscripciones de Foum Chenna se enmarcan en el líbico-bereber de transición (PICHLER, 2008: 187), por lo que podrían ser medievales o, incluso, posteriores. 
alógrafos suman el 2,95 \% con respecto al total del corpus. Las dos variantes redondeadas se localizan también en las estelas del antiguo limes tingitano ${ }^{22}$ y en los paneles rupestres de Draa-Tafilalt y Sous-Masa (Marruecos). ${ }^{23}$

Al ser el único grafema en este orden, probablemente no constituía una consonante relevante para el sistema fonológico líbico-bereber, tratándose quizá de un alófono con valor expresivo, tal y como se documenta en bereber (KossMANN, 1999: 219; NAÏT-ZERRAD, 2002a: 356) y en algunos guanchismos (AcostA, 2017: 24). De hecho, en la antroponimia númida ${ }^{24}$ se observa la variación libre de $s$ y š en el pronombre enclítico oblicuo plural ${ }^{25}$ (alomorfos -sn y -šn) y en el prefijo nominal ${ }^{26}$ (alomorfos $m s-$ y $m \check{s}$-), por lo que seguramente fueron alófonos para los autores de estas estelas. Asimismo, en la actualidad, se ha señalado la palatalización ocasional de la $s$ en cinco dialectos bereberes meridionales. ${ }^{27}$

Según nuestro análisis epigráfico, El Hierro no fue ajeno a este comportamiento, pues aparentemente la palatalización de la *s se produjo en los mismos morfemas, dando lugar a los correspondientes alomorfos. En primer lugar, la observamos en el supuesto prefijo adjetivador de las líneas *NMŠșG ( $\left.{ }^{*} n m s ̌ s ̧ g ~ ¿ ' d e ~ m s ̌ s ̧ g ' ?\right)$, *YNMŠGL (*yan mšgl i'un mšgl'?) (Los Saltos 1.1), *YNMŠKL (“yan mškl i'un $m s ̌ k l$ ?') (Los Letreros 13.2) y, quizá, en *GSNMŠN ( ${ }^{*} g s n$ mšn) (La Candia 1.2). Y, en segundo lugar, se advierte lo mismo en el supuesto pronombre oblicuo de 3 . ${ }^{a}$ persona del plural de *S ¿F?GŠN (La Candia 2.6) y * ¿YW?MNŠN (Barranco del Cuervo 1.1).

\subsection{Orden velar}

\section{El grafema in}

Se trata de una variante característica del alfabeto líbico meridional (MORA, 2021: 47-48), a su vez procedente de la $k$ asimétrica de Dougga (RIL 1) (JuDAs, 1863: 11-12; MARCY, 1936a: 24, 1932: 19; Álvarez, 1964: figura 52; CAMPS, 1978: 158; cf. GALAND, 1966: 33, 1973b). En El Hierro se ha registrado este alógrafo en las inscripciones incisas y su forma redondeada en las piqueteadas. En total, la

22 IAM (Inscriptions Antiques du Maroc) 20, 25 (Galand, 1966: 67, 73) y Thamusida 1 (Ait Ali, 2012: 424). 23 Msemrir 1.4, Ouaremdaz 1.9 y Taouz 1.7 (Rodrigue y PICHLER, 2007).

24 En los epitafios líbicos orientales se adoptó el alógrafo cuadrangular $\amalg$, en lugar de ${ }^{\star}$ (presente en las oficiales de Dougga y en las estelas occidentales o mauretanas). En la escritura púnica, la forma ш es también un alógrafo de la šin $\left(* / \int /\right)$ que parece generalizarse a partir del siglo IV a. n. e. (vid. CunCHILlOS y ZAMORA 1997: 168-170).

25 BRŠN (RIL 186), variante de BRSN (RIL 914); BTŠN (RIL 817); YBLŠN (RIL 571) y KNYŠN (RIL 89), posible variante de KNYSWN (RIL 7: 3).

26 MŠHRNL (RIL 1071); MŠGT (RIL 251); MŠKWR (RIL 476); MŠRT (RIL 413), variante de MSRT (RIL 290); MŠTH (RIL 337), variante de MSTH (RIL 87, 513, 589, 671, 674, 676, 689, 723, 810 y 1033); MŠṬHT (RIL 76); MŠTRT (RIL 284 y 473); MŠW (RIL 139), variante de MSW (vid. Chabot, 1940: XV) y MŠWNT (RIL 447), que podría ser la variante de MWSN (RIL 26 y 915).

27 Concretamente, en el zenaga (TAINe-CHeIKH, 1999: 318), el tetserret (Lux, 2013: 133), el tuareg de Ahaggar (Prasse, 1972: I, 45), así como en Ouargla (Delheure, 1987: 3) y Auyila (Putten, 2014: 14). 
presencia de este grafema representa el 2,95 \%: una cifra cercana a la registrada para la * $k$ líbica meridional.

En cuanto a su valor morfológico, se ha documentado el prefijo $\mathrm{kn}$ - en la antroponimia líbica (Снавот, 1940: хviII; Yoyotтe, 1958: 24; Colin, 1999: 16), que, según nuestro criterio, refleja un sintagma formado por el antiguo artículo ${ }^{28}$ y la preposición 'de'. Además, se ha registrado el sufijo - $k n$ (Colin, 1996: 51-53; JoNGELING, 1984: 60-61, 1994: XVII), que identificamos con el pronombre enclítico de acusativo de 2 a $^{\text {a }}$ persona del plural. Los pronombres de acusativo realizan la función de sujeto en los verbos de cualidad (GALAND, 2002: 273-283; ACOSTA, e.p.) y la de complemento directo en los verbos transitivos (CHAKER, 1985a: 487).

En El Hierro no se detecta la prefijación de *KN, seguramente por la propia evolución de la lengua, aunque quizá sí su sufijación. De hecho, advertimos la conmutación del supuesto pronombre enclítico * $k n$ en el par mínimo ${ }^{*} \mathrm{~N}_{1} \mathrm{RKN}$ (La Caleta 2.1) y *NR (Lomo de Tejeleita 1.3). Asimismo, pudo haberse empleado su singular $(-k)$, dada la conmutación de esta consonante en el par *LMNK (El Tejal 1.4) y *LMN (Rivera 1.2).

\section{El grafeman}

A priori, esta letra resultaba difícil de reconocer por su forma, ya que podría haberse confundido con la ${ }^{*} s_{1}$ de Dougga o con una * $m$ invertida (vid. Снавот, 1940: v). No obstante, a partir del estudio del corpus herreño, hemos constatado que se trataba de un alógrafo redondeado de $\Lambda$, a su vez variante de la letra original 1 con valor */g/ en los alfabetos oriental (СНАвот, op. cit.: ibidem) y occidental (KHAYARI, 2004: 103). Por lo tanto, este grafema parece haber evolucionado de la misma manera que la * $k$, experimentando una ligera inclinación de su ductus, un alargamiento del trazo corto y, finalmente, un redondeamiento de su ángulo. Igualmente, según se extrae de la consulta del RIL (СНАBOT, op. cit.), la *g númida llegó a experimentar los dos primeros pasos, aunque mantuvo su forma aguda. ${ }^{29}$

Hemos comprobado que las diferentes variantes de este grafema $(4,16$ $\%$ en total) se llegaron a emplear para secuencias idénticas. En primer lugar, registramos cinco veces la palabra *GZL en La Caleta, escrita con el alógrafo redondeado (paneles 5.4 y 5.6) y con el anguloso (paneles 4.15 y 5.6). Por otro lado, se advierten las mismas oscilaciones gráficas para la *NG en distintos paneles a principio de línea, que quizá reflejaba la preposición pan-bereber nnig 'sobre,

\footnotetext{
28 En las inscripciones líbicas orientales se observa una vacilación de la velares * $k$ y ${ }^{*} g$, especialmente en los epitafios (en general, posteriores a las oficiales de Dougga). Por ejemplo, encontramos la variante GNSLN (RIL 677) del antropónimo KNS 1 LN, habitual en Dougga (RIL 2, 3, 5, 7 y 11). Probablemente, esto se explique a partir del debilitamiento de la * $k$, que quizá representaba una labiovelar, produciéndose, por tanto, la siguiente evolución: ${ }^{*} / \mathrm{k}^{\mathrm{w}} />* / \mathrm{g}^{\mathrm{w}} />/ \mathrm{w} /$. Ello podría reflejar los resquicios de un orden labiovelar proto-líbico-bereber, tal y como ha propuesto AcosTA (2019a: 165).

29 El mantenimiento de la forma aguda en las inscripciones líbicas parece deberse a que la técnica empleada era mayoritariamente la incisión, tras antes haber realizado un esbozo piqueteado (СНABOT, 1940: 230). Dada la ausencia de metales en Canarias, se recurrió al instrumental lítico, que no resultaba igual de eficaz para ejecutar incisiones prolijas y profundas. Quizá, por ello se prefirió la técnica del piqueteado, ya que favorecía la precisión, permanencia y visualización de los trazos.
} 
encima de' (DALLET, 1982: 553; TAÏFI, 1991: 474; KossmANN, 1999: 148), documentada en la teonimia canaria según Provotelle ${ }^{30}$ (1911: 13). Hemos reconocido esta supuesta preposición a partir de la segmentación del texto con el punto ( ${ }^{*} \mathrm{NG} \cdot \mathrm{RY}$ en La Caleta 2.5) y a través del principio del triliterismo de la raíz en *NGTDT y *NGNRN (La Caleta 5.9). Asimismo, también pudo haberse inscrito en las líneas *NGDBNK (La Candia 2.5) y *NGWSYN (La Caleta 2.1).

\section{El grafemaH}

Se trata de uno de los caracteres propios del alfabeto líbico meridional (MorA, 2021: 50), que más tarde se generalizó en los primeros alfabetos saharianos. Según Aghali-ZaKara y Drouin (2009: 9) y CASAjus (2015: 188-190), representó la consonante $\gamma$ en estas inscripciones antiguas. Es posible que tanto en el líbico meridional como en El Hierro equivaliera también a esta velar faringalizada (*/ $\mathrm{k}^{\varsigma} /$ ), ya que no se documenta su equivalente de Dougga $(\stackrel{\bullet}{\cdot})$. Además, tampoco el grafema $\equiv$ es tan frecuente como para haberlo anotado, tal y como podría haber sucedido en los epitafios orientales. ${ }^{31}$ Por otro lado, este signo tiene una frecuencia muy baja $(0,55 \%)$ : rasgo característico de los fonemas faringalizados del bereber.

A priori, resulta complejo afirmar que $\mathrm{H}$ equivaliera a la desinencia de $1 .^{\mathrm{a}}$ persona del singular $(-\gamma)$, como señalaron AGHALI-ZAKARA y Drouin (2009: 9) para los textos saharianos. Aun así, quizá poseyó un valor gramatical en dos ejemplos en los que se sitúa a final de palabra. La primera, ${ }^{*} \mathrm{HMBQ},{ }^{32}$ corresponde al panel 2.11 del Barranco del Cuervo y deducimos que se trataba de un sufijo al estar precedido por tres consonantes. Por último, se observa su permutación con la * $t$ en el panel 1.1 del Barranco de Tejeleita: *WRYNT WRYNQ :

\subsection{Orden glotal}

El grafemalll

Es un signo relativamente escaso (1,97\%) comparado con su equivalente de los epitafios orientales (10 \%). En cambio, la supuesta */h/ herreña registra una pauta más cercana a la norma oficial de Dougga, donde esta letra comenzaba a alternar con la $t_{1}$ a final de palabra. En las inscripciones herreñas, la glotal aparece

30 «Une particularité qui m’a paru intéressante à signaler à part est le nom que les Sendi donnent à Dieu: Ou gounnej, c'est-à-dire, à proprement parler, celui qui est au-dessus. (...) Ce qui m'a frappé c'est la ressemblance étrange qui existe entre le nom de Dieu chez les anciens Guanches, d'après Viana et Galindo, et le nom qu'emploient les Sendi. Viana donne Hucanech (lisez sans doute Ou-k-anech), Galindo Achucana. N'est-ce pas là le même mot que notre Ou-g-ounnej?» (Provotelle, 1911: 13).

31 El grafema III $(* / \mathrm{h} /)$ quizá acabó reemplazando también a $\div$ en el líbico oriental funerario debido a una supuesta relajación en la articulación del fonema $* / \mathrm{k}^{\varsigma} /$. Sirva de ejemplo actual, la realización [ћ] de la velar faringalizada entre los bereberes de Achtouken (Sous, Marruecos) (LaOust, 1921: 55).

32 Como se verá, empleamos la letra $q$ para representar esta velar, siguiendo la tradición instaurada por Снавот (1940: v). Sin embargo, desconocemos si su realización era sorda o sonora, siendo este un rasgo impertinente para las consonantes faringalizadas de las lenguas afroasiáticas (MARTINET, 1983: 239; ACOSTA, 2019b: 51). 
solo siete veces ${ }^{33}$ en posición final, siendo por el contrario mucho más habitual la ${ }^{*} t$ (14 líneas $)^{34} \mathrm{y}$, sobre todo, su correlato faringalizado: ${ }^{*} t$ (22 líneas). ${ }^{35}$

La diferencia con la ${ }^{*} h$ de los epitafios orientales quizá apunte a cuestiones dialectales, ya que en Numidia se produjo un debilitamiento de la *t final $\left({ }^{*}[\mathrm{t}]>\right.$ $\left.{ }^{*}[\theta]>*[\mathrm{~h}]\right)$, tanto en la lengua líbica como en la púnica, a partir del siglo II a. n. e. (Jongeling, 1984: 83; PutTEN, 2017: 347). En cambio, según se desprende de nuestro estudio epigráfico y de la toponimia (AcostA, 2019a: 199, 211), ese fenómeno no afectó a la modalidad que arribó a El Hierro, seguramente porque provenía de la periferia meridional líbico-bereber. También es posible que la * $h$ final de Canarias no procediera necesariamente del debilitamiento de la * $t$, como se ha propuesto para el líbico oriental. Además, el comportamiento de la *h herreña no es extrapolable al conjunto archipelágico, ya que en otras islas, como Fuerteventura, se observa que la * $h$ final es más habitual. ${ }^{36}$ Quizá, ello se explique porque no representaba realmente una glotal etimológica, sino una vocal, siguiendo el mismo patrón de los epitafios funerarios númidas (de época romana en su mayoría) (MoRA, 2017: 7-8) y de la actual escritura tuareg (Drouin, 2007: 6-7). Dado que, en la escritura líbicobereber, la vocalización es una práctica que suele asociarse al contacto con otras lenguas (AGHALI-ZAKARA, 2014: 5), quizá los autores de las inscripciones majoreras estuvieron más influidos por la romanización. En cualquier caso, se trata de un planteamiento que requiere mayor profundidad y cuyo estudio revelará, con toda seguridad, más datos sobre las gentes que poblaron el Archipiélago.

\subsection{Líquidas}

En aras de la sistematicidad, abordamos aparte el estudio de estos caracteres, ya que se sitúan fuera de la correlación principal. Resulta llamativo que estos grafemas compartan formas ${ }^{37}$ y valores en los alfabetos líbicos (СНАвОт, 1940;

33 * GH (La Caleta 4.2, *NH (Barranco del Cuervo 9.5B), *TTHH (El Tejal 1.2), *WQNFH (Barranco del Cuervo 2.7), *YMRH (La Candia 1.3), *YWDGRH (Camino Ancho 1.1) y *ZK YYNH (Hoyo Blanco 2.3). 34 *GZLSR-T (La Caleta 5.4), *NMṬ ¿T? (Hoyo Blanco 1.2), *NRT (Barranco del Cuervo 1.3), *NRWT (La Caleta 4.14), * N S SRT (Barranco del Cuervo 9.6), *NȚNN 1 T (Barranco del Cuervo 7.1), * RNWNRT (Barranco del Cuervo 9.6), *ȘB ¿FT? (Hoyo Blanco 1.3), *TDKT (La Caleta 5.5), *TKNT (Hoyo Blanco 1.2), * WRYNT (Barranco de Tejeleita 1.1), *WRYT · (La Caleta 5.6), *WYR-T (La Caleta 3.2) y * ¿W?YR-T (La Caleta 2.3)

35 * ¿B?R-TMṬ (La Candia 2.1), *KTṬ (Lomo de Tejeleita 2.6), *LBT • (La Caleta 2.1), *M¿G?TDṬ (La Caleta 5.1), *MNBHṬ (La Caleta 4.4), *MNRṬ (La Candia 1.3), *MSNMGWṬ (Los Letreros 9.4), *NGTDṬ (La Caleta 5.9), *NN ȚGYLṬ (Los Saltos 1.2), *NȘȚȘYDṬ (Los Letreros 11.26), *NṬSṬ (La Candia 1.4), * ¿RH?MGWṬ (La Cueva de Don Gabino 1.2 F), * SŠṬ (Lomo de Tejeleita 3.1), *ŠDṬ (Los Letreros 4.1), *TNGSṬ (La Caleta 5.1), *WDDMṬ (La Caleta 5.2), *WRFDṬ (Camino Ancho 1.1), *WRTFṬ (El Barranquillo 1.1), *YMSṬ (La Caleta 5.1), *Y ¿SṬ? (La Cueva de Don Gabino 1.2 B), *YZNKT (La Candia 1.4) y *¿Z?YTMNT (Barranco del Cuervo 0.0 A).

36 Este grafema aparece en posición final en nueve paneles majoreros: Montaña Blanca 1.6, Cuchillete de Buenavista 1.5, Barranco del Cavadero 1.1 y 2.1, Morro de La Galera 1.1, Montaña del Sombrero 1.1, $1.2,1.4$ y 1.5. En cambio, la *t final solo se inscribió en dos paneles: Montaña Blanca 1.1 y Morro de La Galera 1.2 (vid. Rodrigue y PiCHLeR, 2007).

37 No obstante, hay que aclarar que la semiconsonante $w$ ha experimentado un ligero cambio en los alfabetos tuaregs, simplificando sus dos barras por dos puntos. 
Galand, 1966; Khayari, 2004) y tifinagh (Aghali-ZaKara y Drouin, 2007: 28), lo cual parece deberse a su valor morfemático.

\section{El grafemaU}

$\mathrm{Al}$ igual que en las inscripciones norteafricanas, se observa que este signo poseyó una frecuencia elevada $(8,10 \%)$ y que acostumbraba a situarse a comienzo de palabra, tal y como se observa en 24 líneas. ${ }^{38}$ Por lo tanto, seguramente representó también la consonante */m/ en El Hierro, que en las lenguas líbico-bereberes y otras del phylum afroasiático funciona como prefijo adjetivador, de nomen agentis y de nomen loci. El agentivo es habitual en el corpus líbico, empleándose para los títulos, los nombres de funciones y los etnónimos. Igualmente, algunos topónimos bereberes presentan este prefijo, en cuyo caso designa su carácter locativo o una cualidad asociada al terreno. Aunque seguramente la ${ }^{*} m$ - inicial equivalía a tal prefijo en la mayoría de las inscripciones herreñas, solo advertimos un par mínimo donde parece conmutar: *NY (Barranco de Tejeleita 0.1) frente a *MNY (Camino Ancho 1.1).

Por otro lado, cabe recordar que documentamos también el agentivo unido al prefijo de nomen loci, causativo y factitivo (s-) para formar el prefijo adjetivador denominal *ms-. Por consiguiente, las palabras que lo contienen quizá designaban antropónimos, títulos, cualidades, etc.

\section{El grafema-}

Se trata del signo más abundante del corpus herreño (15,21 \%). Seguramente, ello se debía a las múltiples funciones de la consonante representada $(* / n /)$. Asimismo, consideramos que los caracteres - $\left({ }^{*} n\right)$ y $\mid\left({ }^{*} n_{1}\right)$ son variantes, tal y como parece haber sucedido en el líbico occidental (GALAND, 1966: 25), donde se produjeron oscilaciones de su posición (vid. Ait Ali, 2012: 573). De hecho, en seis inscripciones herreñas ${ }^{39}$ advertimos una norma ortográfica característica del líbico: ${ }^{40}$ la inclinación o rotación de la * $n$ cuando acompaña a otra ${ }^{*} n$ o a un signo formado por barras, con el fin de evitar su confusión con la * $l$ o la * $h$ rotada.

Con respecto al comportamiento de este grafema, observamos su alta

38 *M[...]¿L? (La Caleta 4.6), *M[...]NFȘ (Los Letreros 9.4), *MBK (La Caleta 4.6), *M¿G?TDṬ (La Caleta 5.1), ${ }^{*}$ M?HFGN (Barranco del Cuervo 0.17), *MKYN $i$ D? (Barranco del Cuervo 9.5A), *ML (El Tejal 1.1), *MMLiR? (Piedra del Cabildo), *MN (Hoyo Blanco 2.1), *MNBHT (La Caleta 4.4), *MN ${ }_{1} \mathrm{~L}_{(\mathrm{Los}}$ Saltos 4.1), *MNM (Los Letreros 6.4), *MNRṬ (La Candia 1.3), * MNY (Camino Ancho 1.1), *MRMNYW (La Caleta 4.10), * $\mathrm{MRN}_{1}$ (Barranco del Cuervo 6.2), *MSM (Los Letreros 5.8), *MSNMGWṬ (Los Letreros 9.4), *MSRYN (La Caleta 4.10), *MṬL (La Caleta 5.6), *MZG (La Cueva de Don Gabino 1.3) y ${ }^{*}$ MR-TW (La Caleta 5.9).

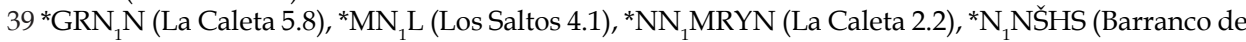
Tejeleita 2.6), *NN $N_{1}$ TGYLṬ (Los Saltos 1.2) y *NȚNN 1 T (Barranco del Cuervo 7.1).

40 En las palabras NFRTLN y FS LN $_{1}$ (RIL 6 de Dougga) se observa que las $n(I)$ se trazaron inclinadas junto a la $l(\|)$. Asimismo, se observa el mismo comportamiento para las ${ }^{*} n$ de las inscripciones occidentales RIL 839 y 853. 
frecuencia a principio y final de línea. Por lo tanto, la letra - cumplió seguramente varias funciones características del líbico y de las lenguas bereberes como expondremos a continuación.

La * $n$ inicial pudo equivaler al alomorfo alveolar del prefijo agentivo * $m$ - ante radicales labiales, patente en el líbico oriental (RössLER, 1958: 102-103) y el bereber (Prasse, 1974: 67, 1972: 159; Heath, 2005: 552) o a la preposición de genitivo $n$ 'de', muy habitual en las inscripciones del limes tingitano, según El KHAYARI (2004: 104).

En El Hierro parece constatarse ambos comportamientos. En primer lugar, se observan dos ejemplos en los que el supuesto alomorfo agentivo se prefijó a raíces triconsonánticas con radical labial: *NMDL (Barranco del Cuervo 6.4) y ${ }^{*} \mathrm{~N}_{1} \mathrm{MRZ}$ (Barranco del Cuervo 1.1). Además, encontramos un par mínimo donde pudo haber conmutación: *NMRN (Barranco de Tejeleita 0.1) frente a * ${ }^{*} \mathrm{~N}_{1}$ (Barranco del Cuervo 6.2). En segundo lugar, el valor preposicional de ${ }^{*} n$ se evidencia a través de su conmutación en el par mínimo * ${ }_{1}$ NSSHSN (Barranco de Tejeleita 2.6) frente a *NŠHSN (Barranco de Tejeleita 2.3). En este caso, descartamos que la ${ }^{*} n$ equivalga al prefijo de nomen agentis, ya que no existen consonantes labiales en la supuesta raíz ( $\left.{ }^{*} \mathrm{NSS} H\right){ }_{,}^{41}$ cosa que no podemos hacer en los tres ejemplos anteriores, pues cabría la posibilidad de que ${ }^{*} n$ - reflejara la preposición de genitivo ante sustantivos agentivos que comienzan por ${ }^{*} m$ -

$\mathrm{La}^{*} n$ final es especialmente habitual en las inscripciones líbicas, tal y como señaló LETOURNEUx (1878: 65) por primera vez. Igualmente, este comportamiento parece haberse trasladado a la escritura herreña. Quizá, la * $n$ final respondía a dos funciones distintas: un sufijo verbonominal de plural y un sufijo adjetival. La marca de plural está claramente presente en los pronombres oblicuos de $3{ }^{a}{ }^{a}$ persona $(-s n)^{42}$ que abordamos en el orden alveolar. No obstante, desconocemos si las ${ }^{*} n$ finales de los casos siguientes representaron un plural verbonominal o un sufijo adjetival: ${ }^{43}{ }^{*} \mathrm{FRRN}$ (La Cueva de Las Chivas 1.5), ${ }^{*} \mathrm{GRN}_{1} \mathrm{~N}$ (La Caleta 5.8), *MSYN (Barranco de Tejeleita 2.6), *MSRYN (La Caleta 4.10), *NBṬSMN (La Candia 1.2), *NFZYN (Barranco de Tejeleita 2.3), *NGWSYN (La Caleta 2.1), *NTZMN (La Candia 1.2), *ŠFZRN (Hoyo Blanco 1.2), *TSNRN (La Cueva del Agua 1.1), ${ }^{*}$ WLRMN (Lomo de Tejeleita 1.6) y *ZYZYN (Barranco del Cuervo 2.4).

\section{El grafema $=$}

Corresponde a la */1/ en los alfabetos conocidos y, quizá, también en el herreño, donde posee una presencia idéntica a la númida funeraria: ${ }^{44} 4 \%$.

41 Excluimos de la raíz la terminación * $\mathrm{SN}$ porque parece corresponder al pronombre enclítico oblicuo de 3 . $^{\text {a }}$ persona del plural.

42 Este pronombre está compuesto por la -s de $3 .^{a}$ persona singular del oblicuo y la $-n$ del plural.

43 CHAKER (1985b: 5) describió tres patrones adjetivales bereberes constituidos de la siguiente manera: «(a)ccan, (a)cc can, (a)cvcan». No obstante, su identificación en las inscripciones es más compleja debido a la ausencia de vocales.

44 La variedad de Dougga presenta la frecuencia más elevada para la consonante $l(6,25 \%)$, ello se debe al empleo reiterado de la palabra gld 'rey'. 
Aparentemente, no desempeñó ninguna función gramatical, aunque JoNGELING (1994: XIX) señaló que era muy frecuente a final de palabra en la onomástica líbica, patrón que hemos observado en diecisiete inscripciones herreñas. ${ }^{45}$

En definitiva, la función de esta consonante parece haber sido fundamentalmente léxica, revelando algunas raíces pan-bereberes habituales. Concretamente, destacaríamos las contenidas en las palabras *GZL e *YGLD.

La secuencia *GZL se inscribió cinco veces en tres paneles de La Caleta (4.15, 5.4 y 5.6) y parece corresponder a la raíz GZL 'ser corto' (NAÏT-ZERRAD, 2002b: III, 931-932). Por lo tanto, podría tratarse de un antropónimo, apodo o de un etnónimo, quizá vinculado a los guezulas: una extensa tribu senhaya que VycicHL (1955) identificó con los antiguos gétulos ${ }^{46}$ y que, durante el medievo, ya se habían extendido hasta el Sáhara occidental (CAMPS, 1999). No obstante, el análisis epigráfico per se solo nos ofrece esta hipótesis de partida que merece un estudio histórico exhaustivo antes de extraer conclusiones definitivas de esta índole.

La palabra *YGLD (Barranco del Cuervo 0.17) estaba formada aparentemente por la desinencia verbal de 3. a persona masculina singular ( $y$-) más una raíz trilítera *GLD, que parece ser la misma que la del título gld 'rey' (PRASSE, 1972: I-III, 158) de las inscripciones oficiales de Dougga. De ser así, habría diferencias de conjugación entre ambas regiones. Así, el caso herreño se basaría en la de los verbos activos, mientras que en la ciudad númida parece haberse seguido la de los verbos de estado y cualidad. ${ }^{47}$ Este tipo de conjugación, hoy en desuso, consiste en sufijar a la raíz los pronombres personales de acusativo (GALAND, 2002: 273-283). Por otro lado, también cabría la posibilidad de que la secuencia *YGLD estuviera formada por la preposición bereber y ‘a, para' y un sustantivo gld. Desde nuestro punto de vista, la segunda hipótesis resulta menos convincente, ya que no se ha documentado este tipo de fórmulas en el corpus líbico, ni tampoco dicha preposición.

\section{El grafema $\bigcirc$}

Este signo común en los alfabetos transcritos representaba el fonema * $\mathrm{f}$ / y poseía una frecuencia relativamente elevada en las inscripciones norteafricanas, especialmente en las estelas del limes y en las rupestres meridionales. En El Hierro, observamos un patrón similar, teniendo una presencia del 9,74 \%.

45 *GL (Hoyo Blanco 1.7), *GZL (La Caleta 4.15, 5.4 y 5.6), *HR-TRTL (La Cueva de Don Gabino 1.2 A), *LL (Barranco del Cuervo 5.1), * M[...]¿L? (La Caleta 4.6), * ML (El Tejal 1.1), * MN 1 L (Los Saltos 4.1), ${ }^{*}$ MȚL (La Caleta 5.6), *NMDL (Barranco del Cuervo 6.4), *RL (Piedra del Cabildo), *[...]SML (Guarazoca), *ك̌ $\cdot \mathrm{L}$ (La Caleta 4.4), "WMBYW-RL (La Candia 1.2), *WZWRL (La Candia 1.2), *YDKL (Hoyo Blanco 1.2), *YNMŠGL (Los Saltos 1.1) y *YNMŠKL (Los Letreros 13.2).

46 Cabe señalar que los gétulos conformaban un conjunto heterogéneo de pueblos nómadas y seminómadas que se situaban en la franja presahariana, limítrofe con el imperio romano (DESANGES, 1962). Dicha franja correspondía al ámbito de extensión del alfabeto líbico meridional (MorA, 2021).

47 Se trata de un modelo de conjugación arcaico que se mantiene de forma dispar en algunos dialectos bereberes, difiriendo en los aspectos y personas verbales. En el habla de los Ayt Ziyan (Pequeña Cabilia) se observa la pauta más conservadora (GALAND, 2002: 273-283). 
Tanto en el continente como en Canarias, ${ }^{48}$ este grafema acostumbraba a escribirse tras la ${ }^{*} w$, sobre todo a principio de palabra. ${ }^{49}$ Por consiguiente, parecía corresponder al adverbio de negación *wr. De hecho, podemos confirmar su carácter morfemático a partir de la segmentación del texto mediante el punto en *WR ·NS (Lomo de Tejeleita 1.7) y *WR ·TZ (La Caleta 5.7).

El empleo de este adverbio a comienzo de palabra es habitual en la antroponimia y la teonimia líbico-bereberes desde la Antigüedad hasta hoy. En efecto, su existencia se retrotrae a algunos nombres de los jefes libios ${ }^{50}$ recogidos en las inscripciones jeroglíficas egipcias (YOYOTTE, 1958: 23; CoLIN, 1996: II, 14). También entre los númidas, contamos con significativos ejemplos de antropónimos ${ }^{51}$ y teónimos ${ }^{52}$ que comienzan por este adverbio (CAMPS, 1990: 144145; JonGELING, 1994: 14). Durante el medievo, la tradición se trasladó además a los gentilicios, ya que muchos se gestaron a partir de patronímicos. Finalmente, esta costumbre se ha conservado entre los tuaregs, quienes usan nombres personales construidos por el adverbio de negación más un sustantivo ('sin ...') o más un verbo en 3. ${ }^{a}$ persona ${ }^{53}$ ('él/ella no...) (CHAKER, 1985a: 488). En definitiva, resulta congruente que los aborígenes canarios portaran este tipo de antropónimos, pues, al fin y al cabo, poseían el mismo bagaje cultural.

\section{El grafema}

Este signo parece haber representado un morfema debido a su alta frecuencia $(7,33 \%)$, a su comportamiento y al ejemplo norteafricano, donde posee valor * $y$ $(* / \mathrm{j} /)$. Por lo tanto, seguramente equivalió también a la desinencia de $3 .^{a}$ persona del masculino singular ( ${ }^{*} y$-). En efecto, observamos varios pares mínimos que lo confirmarían. En primer lugar, se advierte su conmutación en *YNM (La Cueva de Don Gabino 1.2 B) frente a *NM (La Caleta 5.6). Por otro lado, además de la

48 Además de en El Hierro, se documenta esta sucesión en Gran Canaria (La Angostura, Barranco de Balos y Hoya de Toledo), Lanzarote (Peña de Luis Cabrera y Femés) y Fuerteventura (Montaña Blanca) (vid. C.H.E.C., 1988; Cuenca, 1996; Springer, 1996; Ulbrich, 1996; Rodrigue y Pichler, 2007).

49 En El Hierro distinguimos las siguientes líneas con la secuencia *WR: *WR (La Candia 2.7), ${ }^{*} W R$.NS (Lomo de Tejeleita 1.7), *WR TZ (La Caleta 5.7), *WRFDT (Camino Ancho 1.1), *WRKYS (La Cueva Don Gabino 1.4), *WRLBR (Barranco de Tejeleita 4.1), *WRN (Barranco del Cuervo 8.2), *WRN (La Candia 1.3), *WRTFT (El Barranquillo 1.1), *WRYNQ (Barranco de Tejeleita 1.1), * WRYNT (Barranco de Tejeleita 1.1), *WRYT (La Caleta 5.6), *WZWRL (La Candia 1.2), * YTRWRN (La Candia 1.2), *MSWRN 1 (La Cueva de Don Gabino 1.2) y *ŠNŠWRN (La Cueva del Agua 1.1).

$50 \mathrm{Tal}$ es el caso de $W r$ ? $m r$ : «L'un des grands personnages libyens dont ses compatriotes constatent, dans le récit de la campagne de l'an 5 de Ramsès III, qu'ils ont été anéantis par le roi» (CoLIN, 1996: II, 20).

51 En las inscripciones líbicas orientales encontramos los siguientes antropónimos: $\mathrm{WRS}_{1} \mathrm{~K}_{1} \mathrm{~N}$ (RIL 1: 5), WR[...] (RIL 932), WRH (RIL 180), WRGDHN (RIL 117), WRMRSN (RIL 262), WRMRT (RIL 802), WRMZ (RIL 286, 318, 319, 397. 421 y 942), WRMH[Z] (RIL 230), WRT (RIL 945), WRZ[F] (RIL 523) y WRZR[F] (RIL 670).

52 CAMPS (1990: 144-145) extrajo de las inscripciones latinas los siguientes nombres de divinidades que contenían este prefijo adverbial: VARRICCALA, VARSis, VARSisSima y VARSUTINA.

53 «Wer-Ilemmed 'Il n'apprend pas' < du verbe elmed 'apprendre'; Wer-tenezzu 'elle n'est pas à vendre' < du verbe enz 'vendre / acheter'» (AgHALI-ZAKARA, 2003: 221) . «Our-iekkoul ('il ne prend pas souci'), Our-toukil ('elle n'est pas perdue')» (FOUCAULD y BASSET, 1940: 329-331). 
conmutación de la desinencia, vemos la permutación por su equivalente femenina ( ${ }^{*} t$-) ante la supuesta raíz * $R N$ en las líneas siguientes: *YRN (Barranco del Cuervo 1.1), * RN (La Cueva de las Chivas 1.2), * $\mathrm{RN}_{1}$ (Arenas Blancas 1.1) y * $\mathrm{TRN}_{1}$ (La Cueva del Agua 1.1).

Cabe señalar que esta letra poseía diversos alógrafos $(\varkappa, \backsim, 2$, etc.), siendo el de trazos cuadrangulares el más habitual en El Hierro. Esta variante se documenta en las estelas del limes de la Mauretania Tingitana (IAM $\left.{ }^{54} 20\right)$ y en algunas inscripciones rupestre ${ }^{55}$ del Draa-Tafilalt y el Sáhara occidental.

\section{El grafema $\|$}

Al igual que el signo anterior, parece representar una semiconsonante, en este caso la velar */w/. Nuevamente, nos apoyamos en su elevada frecuencia $(6,13$ $\%)$, su comportamiento y en la comparación con los alfabetos norteafricanos. En efecto, este grafema era habitual en las inscripciones líbicas porque representaba el sustantivo * $w$ 'hijo' con el que se construía el patronímico del personaje homenajeado o fallecido, por ejemplo: MSNSN GLDT WGYY (RIL 2: 6) ‘Masinisa rey, hijo de Gaya'. En segundo lugar, se encuentra también en menor cantidad en el adverbio de negación *wr del que ya hablamos, tanto en El Hierro como en el norte de África. Por último, la *w inicial podría, además, explicarse a partir del artículo masculino bereber wa/wi que, por el contrario, no parece haberse empleado en las estelas líbicas. En efecto, CHAKER (1985a: 487) señaló la ausencia del artículo y del sintagma wan/win 'el de, lo de'. Por el contrario, se registran numerosos antropónimos númidas con los prefijos $k$ - y kn- que, según nuestro criterio, podrían corresponder, respectivamente, a un estado arcaico de wa/wi y wan/win.

En El Hierro existen numerosos ejemplos de la *w a comienzo de palabra, ${ }^{56}$ por lo que quizá se trate del sustantivo en aposición 'hijo', o bien de un estado reciente del artículo bereber, ${ }^{57}$ pues no documentamos el prefijo ${ }^{*} k n \sim{ }^{*} g n$. De hecho, advertimos la función morfemática de *w- a partir de su conmutación en los ejemplos siguientes: *WYṬ (La Candia 2.4) frente a *YṬT (Barranco de Tejeleita 2.6) e *YṬNWW ${ }^{58}$ (El Tejal 1.2). No obstante, habría que desarrollar un estudio más complejo antes de decantarnos por la función que desempeñó la *w inicial en cada caso.

54 La sigla IAM alude a la obra Inscriptions Antiques du Maroc (GALAND, 1966), que contiene gran parte del corpus líbico occidental.

55 Nos referimos a las inscripciones marroquíes de Hayart 1.8, Oudraz 1.4 y Taouz 1.1 y 1.3 (RODRIGUE y Pichler, 2007) y a las saharianas occidentales de Leyuad VI y Assaig Bedrag 1 y 2 (GALAND, 1976).

56 *WDDMT (La Caleta 5.2), *WKSN (La Caleta 4.2, 5.4 y 5.5), *WLRMN (Lomo de Tejeleita 1.6), *WMBYW-RL (La Candia 1.2), *WMK (Barranco del Cuervo 2.6), * $\mathrm{WN}_{1}$ (La Caleta 1.1), *WQNFH (Barranco del Cuervo 2.7), *WS Q ?S (La Caleta 2.3), *WSRF (Camino Ancho 1.1), *WYR-T (La Caleta 2.3 y 3.2), *WYT (La Candia 2.4) y *WZWRL (La Candia 1.2).

$57 \mathrm{El}$ artículo wa parece haberse generalizado en el medievo, según se desprende de la antroponimia (CHAKER, 1985a: 489). Quizá, ello se debía a la culminación del debilitamiento de la * $/ \mathrm{k}^{\mathrm{w}} /$.

58 Esta línea parece estar formada por * YṬ más *GNW, que localizamos también en *SRGNW (La Candia 1.3). 


\subsection{Los dígrafos}

Estos signos corresponden a uniones de dos consonantes, por lo que no se incluyen dentro del sistema fonológico. Los dígrafos o ligaduras no se han documentado en los antiguos alfabetos líbicos septentrionales, por lo que parecen ser relativamente modernos (PrASSE, 1972: I-III, 147). Ciertamente, son bien conocidos en los alfabetos tifinagh actuales, especialmente en Níger y Mali, estando en desuso en Ahaggar (SAVAGE, 2012: 116). Dado que estos signos se registran también en algunas inscripciones rupestres meridionales y en Canarias, parece tratarse de un recurso, además de tardío, originario del ámbito presahariano.

Tradicionalmente, el empleo y la comprensión de los dígrafos están reservados a los usuarios y lectores más experimentados. Su uso indica la ausencia de vocal entre las dos consonantes ligadas, las cuales, consiguientemente, forman un grupo tautosilábico ${ }^{59}$ (cuando las consonantes pertenecen a la misma sílaba) o heterosilábico (cuando las consonantes pertenecen a sílabas distintas). Por lo tanto, indirectamente, tales grupos indican también que las demás consonantes contienen vocales. Los dígrafos se emplean fundamentalmente para desambiguar aquellas palabras que poseen las mismas consonantes, pero una vocalización diferente, por ejemplo: $+[\oplus$ [tămárt] 'barba' frente a +[O+ [témərit] 'mujer amable' (SAVAGE, op. cit.).

\section{El dígrafo $\oplus$}

Este signo representa la ligadura $r t$ en la escritura tuareg (PRASSE, 1972: 157; Drouin, 2011: 9). Además, lo encontramos en las inscripciones rupestres antiguas ${ }^{60}$ de Sous-Masa y Draa-Tafilalt, así como en el líbico-bereber de transición o medieval. Se desconoce si este carácter representó siempre el mismo valor en toda su área de influencia. No obstante, a continuación, nos ceñiremos al análisis del corpus de El Hierro.

El signo $\oplus$ tuvo un uso anecdótico en la escritura herreña, concentrándose en la mitad septentrional de la Isla ${ }^{61}$ y representando únicamente el $0,77 \%$ del total. Además, en La Caleta (2.1, 2.4, 3.2 y 5.4) y el Barranco del Cuervo (1.1 y 2.3), se documenta el signo $\oplus$ que parece ser un alógrafo, ya que ambas variantes se emplearon para la misma secuencia: *WYR-T (La Caleta 2.3 y 3.2).

Con respecto a su valor fonológico, pensamos que pudo representar también la ligadura $r t$ (que anotamos * $\mathrm{R}-\mathrm{T}$ ) por las razones que a continuación exponemos. Primeramente, encontramos este signo en la línea *TMR-TN (La Cueva del Agua 1.2), donde la ${ }^{*} t$ de la ligadura parece corresponder a la del pronombre enclítico de $3^{\text {a }}$ persona plural de acusativo $(-t n)$. En cuanto a la ${ }^{*} r$, quizá era un radical de la

59 La ligadura tautosilábica es menos frecuente y se sitúa a final de palabra, adecuándose a la silabación tuareg (SAVAGE, 2012: 100).

60 Estas inscripciones se encuentran en los yacimientos marroquíes de Taouz, Iourarhane y Ouaremdaz (Rodrigue y PichleR, 2007).

61 Se documenta en el Barranco del Cuervo (9.6), La Cueva del Agua (1.2), La Cueva de Don Gabino (1.2), La Caleta (2.3 y 5.9), La Candia (2.1) y en el tablón del Hoyo de los Muertos (Guarazoca). 
raíz * $M R$, abundante en el conjunto epigráfico insular y que, igualmente, parece documentarse en la secuencia *MR-TW (La Caleta 5.9). Por otro lado, el valor * $r$ puede explicarse a partir de otras palabras reconocibles en el corpus herreño. Así, la línea *GZLSR-T (La Caleta 5.4) parece formada por las palabras *GZL (La Caleta 4.1 y 5.6) y *SRT (recogida aisladamente en el Barranco del Cuervo 9.6). Finalmente, la *t de este dígrafo quizá correspondía al prefijo verbonominal de género femenino $t$ - en las siguientes líneas: *BR-TMT (La Candia 2.1), *HR-TRTL (La Cueva de Don Gabino 1.2), *GR-TNK (La Caleta 2.4), *NR-TNWN (Barranco del Cuervo 2.3), *NR-TRN (La Caleta 2.1), *NR-TWLN (Barranco del Cuervo 1.1) y, quizá, *R-TNS (La Cueva de Don Gabino 1.2).

\section{El dígrafo $\mathbb{D}$}

Posee un uso muy restringido en el norte de África, concretamente en las inscripciones rupestres de Ifigha (Tizi Ouzzou), donde se han registrado cuatro recurrencias (vid. Poyto y Musso, 1969). Aparentemente, el alfabeto empleado en este abrigo de La Cabilia pertenecía a la modalidad meridional, a pesar de situarse en pleno Tell argelino. ${ }^{62}$ También en Canarias es un signo poco común, pues además de contabilizarse dos ejemplares en Gran Canaria ${ }^{63}$ y Lanzarote, ${ }^{64}$ se documentan solamente cuatro en El Hierro (La Candia 1.2, Barranco de San Juan 1.1 y Los Letreros 4.1), que suponen el 0,44\% del corpus insular.

Al igual que el signo anterior, creemos que $\mathbb{D}$ representó una ligadura, concretamente *wr. Nuestra conclusión no solo se apoya en la forma del grafema, sino también en la frecuencia del supuesto adverbio de negación líbico-bereber wr. Quizá, la habitualidad de este morfema llevó a los usuarios de la escritura a crear este dígrafo para representarlo o, por el contrario, para señalar que no se trataba de este adverbio. Dado que entre las consonantes ligadas no existe vocal, en el caso de que reflejara la negación, la secuencia posterior podría corresponder a un sintagma verbal, ya que CHAKER (1985a: 488) precisó que los tuaregs empleaban la forma wr ante verbos, reservando su variante vocalizada war ante sustantivos. Por otro lado, si nos atenemos al patrón tradicional, las ligaduras tautosilábicas deberían situarse únicamente a final de palabra (SAVAGE, 2012: 100). Sin embargo, el dígrafo solo ocupa esta posición en una de las cuatro líneas herreñas. ${ }^{65}$ Por lo tanto, para los casos restantes, habría que considerar la posibilidad de que la ligadura contuviera un grupo heterosilábico, como concluimos para la $\oplus$ en

62 Durante la Antigüedad, los montañeses del Tell argelino llevaron a cabo una economía nómada que aprovechaba las diferencias climáticas latitudinales del territorio norteafricano: montaña, llanura y desierto. Así, durante el invierno, descendían a la llanura para beneficiarse de los pastos y sembrar en las inmediaciones de los ríos. Por el contrario, cuando las lluvias no eran propicias, se desplazaban con el ganado hacia las regiones saharianas anexas (BÉNABOU, 1976: 72). Es probable que estas migraciones estacionales expliquen la presencia del alfabeto líbico meridional en la Cabilia, así como cierta influencia cenete en su dialecto (SOUAG, 2017).

63 El grafema 4 está en el denominado panel n. 3 del Barranco de Balos (SPRINGER, 1996: 415).

64 UlbRich (1996: 355) calcó este signo en el panel A2 de la Peña de Luis Cabrera.

65 *KRŠ ¿W-R? (Los Letreros 4.1), ${ }^{*}{ }^{*} N_{1}$ ?WW-RZRN (La Candia 1.2), *WMBYW-RL (La Candia 1.2) y *YQW-RSTS (Barranco de San Juan 1.1). 
la Isla. En este supuesto, la *w quizá correspondía al sustantivo 'hijo', o bien al artículo, mientras que la ${ }^{*} r$ podría ser el radical inicial de un antropónimo ${ }^{66} \mathrm{o}$ cualquier otro sustantivo. En definitiva, para el comportamiento de esta ligadura, barajamos diferentes explicaciones en las que habría que profundizar antes de decantarnos por la más verosímil.

\section{PROPUESTA DE SISTEMA FONOLÓGICO}

Tras el análisis del corpus alfabético herreño, exponemos nuestra propuesta de sistema fonológico de tres series y seis órdenes. Esta organización parte de los estudios del bereber (AcostA, 2019a: 195, 2019b: 47) y de otras lenguas del phylum afroasiático (MARTINET, 1983: 242; CANTINEAU, 1960: 21). De ellos se desprende la correlación, dentro de cada orden, de las series sorda, sonora y faringalizada ${ }^{67}$ que pudo estar motivada, en origen, por una oposición gradual en la apertura de la glotis (ACOSTA, 2019b: 40). Finalmente, para garantizar la sistematicidad, hemos representado aparte las consonantes líquidas.

Este sistema fonológico coincide en su práctica totalidad con el diasistema bereber de André BASSET (1952: 5) y Galand (1960: 1217) ( $c f$. Kossmann, 1999: 249). Debe tenerse en cuenta que los sistemas solamente reflejan valores fonológicos, prescindiendo de las realizaciones efectivas de cada uno de los fonemas a lo largo de la dilatada historia de la lengua líbico-bereber insular (ca. siglos II-XV d. n. e.). Tales datos solo son accesibles a través del estudio sistemático de la onomástica y del léxico aborígenes, siendo necesario un análisis histórico-comparativo que considere el contacto con las lenguas románicas de los siglos XV al XVII.

TABLA 1

Propuesta de sistema fonológico del líbico-bereber herreño (correlación principal)

\begin{tabular}{|c|c|c|c|c|c|c|c|c|c|c|c|c|}
\hline & \multicolumn{2}{|c|}{ Labial } & \multicolumn{2}{|c|}{ Dental } & \multicolumn{2}{|c|}{ Alveolar } & \multicolumn{2}{|c|}{ Palatal } & \multicolumn{2}{|c|}{ Velar } & \multicolumn{2}{|c|}{ Glotal } \\
\hline Sorda & $* / f \mid$ & $\theta$ & & t & $* / s /$ & $\theta$ & & $\omega 0$ & & in & $* / \mathrm{h} /$ & ||| \\
\hline Sonora & $* / b$ & $\odot$ & $* d \mathrm{~d}$ & {[} & & $\mathrm{H}$ & & & ${ }^{*} / g /$ & $n$ & & \\
\hline Faringalizada & & & $*|t| t$ & ш & $* / s^{s} /$ & T & & & $* / \mathrm{k}^{\mathrm{s}}$ & H & & \\
\hline
\end{tabular}

Fuente: Elaboración propia.

66 No obstante, los antropónimos líbicos que comienzan por esta consonante no son muy habituales (vid. СНАвот, 1940: ххI).

67 Además, hay que sumar la oposición consonántica laxa-tensa que aquí no hemos incluido, dado que la escritura líbico-bereber no representa la geminación. 
TABLA 2

Propuesta de sistema fonológico del líbico-bereber herreño (líquidas)

\begin{tabular}{|c|c|c|c|c|c|c|c|c|}
\hline & \multicolumn{2}{|c|}{ Labial } & \multicolumn{2}{|c|}{ Alveolar } & \multicolumn{2}{|c|}{ Palatal } & \multicolumn{2}{|c|}{ Velar } \\
\hline Nasal & $* / \mathrm{m}$ & $\sqcup$ & $* / \mathrm{n} /$ & - & & & & \\
\hline Lateral & & & $* / 1 /$ & $=$ & & & & \\
\hline Vibrante & & & $* / \mathrm{r} /$ & 0 & & & & \\
\hline Semivocal & & & & & $* / \mathrm{j} /$ & เл & $* / \mathrm{w} /$ & $\|$ \\
\hline
\end{tabular}

Fuente: Elaboración propia.

\section{CONCLUSIONES}

Frente a la disparidad de las «transcripciones» apriorísticas del líbico-bereber canario, proponemos un estudio basado en un método solvente y falsable, aplicado con anterioridad a la epigrafía líbica (RössLER, 1958; CHAKER, 1985a; JoNGELING, 1984, 1994; KHAYARI, 2004; etc.). Tal y como recomendaba СHADWICK (1962: 41-42) para la descodificación de las escrituras desconocidas, este procedimiento se ha fundamentado en el análisis interno de las inscripciones. Para ello, nos hemos apoyado en la morfología gramatical líbico-bereber, pues esta constituye un inventario cerrado de unidades mínimas con significado invariante.

A partir del análisis interno del corpus herreño, hemos obtenido diversas conclusiones. En primer lugar, se detectan morfemas gramaticales característicos de las lenguas líbico-bereberes, como los afijos verbonominales, pronombres personales, adverbios, preposiciones y conjunciones. Además, la mayoría de ellos se documenta en las estelas líbicas orientales, lo que indica un innegable parentesco histórico con Numidia: foco cultural líbico-bereber por excelencia. Como estos morfemas son reconocibles en la onomástica númida, es posible que muchas de las inscripciones herreñas contuvieran antropónimos y, quizá, también etnónimos. Por otro lado, se observa un vínculo evidente con la periferia meridional norteafricana que trasciende del contexto rural y del soporte rupestre. En efecto, la epigrafía insular revela rasgos lingüísticos de los actuales dialectos bereberes meridionales, como la variación libre de $* / s / \sim^{*} / \int / \mathrm{y} \mathrm{de} * / t / \sim^{*} / \mathrm{t}^{\mathrm{t}} /$. Cabe destacar que esta oscilación se ve más acentuada en el sur de El Hierro, quizá por su aislamiento de la costa de Valverde, donde se concentran las inscripciones. Asimismo, tal disparidad podría estar motivada por la propia evolución de la 
lengua durante este largo periodo histórico, o bien por diferencias socioculturales. En este sentido, cabe señalar que en la franja septentrional se registran más ligaduras, cuyo conocimiento supone un dominio de la escritura.

Los resultados del análisis morfofonológico casan con nuestra propuesta clasificatoria del líbico-bereber canario. Según esta hipótesis, el alfabeto que se trasplantó en el Archipiélago procedía de una variedad presahariana tardía, descendiente, a su vez, de la norma oficial de Dougga. Dada la concentración de estos marcadores alfabéticos en Tafilalt, valles del Sous y Draa y en el Sáhara occidental, los primeros pobladores de las Islas debieron de venir desde la vecina costa norteafricana (MorA, 2021). Asimismo, debido a la homogeneidad alfabética que presentan las inscripciones líbico-bereberes canarias (SPRINGER, 2017), este ensayo de transcripción del corpus herreño puede servir como punto de partida para la investigación del conjunto canario.

En definitiva, el estudio de la escritura nos está desvelando tímida, pero consistentemente, los únicos testimonios directos de los aborígenes canarios. De esta manera, la epigrafía nos proporciona una valiosa información sobre este periodo de la historia canaria y norteafricana, difícilmente perceptible a través de otras disciplinas.

\section{REFERENCIAS}

Acosta Armas, J. (2017): «Notas sobre la aspiración en los guanchismos», Revista de Filología, 35: 9-49.

Acosta Armas, J. (2019a): «Gramática de la toponimia herreña de origen bereber», en J. J. BAtista RodríGuez (ed.), Estudios sobre toponimia canaria prehispánica. Sobre guanchismos, topónimos guanches y lingüística bereber, Academia Canaria de la Lengua, Santa Cruz de Tenerife: 151-222.

Acosta Armas, J. (2019b): «Notas sobre la espirantización de */t/ bereber en los guanchismos», Revista de Filología, 39: 13-70.

Acosta ARMAS, J. (en prensa): «Aproximación a la génesis del sistema pronominal personal bereber», en VII Coloquio de Lingüística del Instituto Universitario de Lingüística Andrés Bello.

Aghali-ZaKara, M. (2003): «Anthroponymie touarègue. Dénominations multiples des individualités», Nouvelle revue d'onomastique, 41-42: 221-229.

Aghali-ZaKara, M. (2014): «À propos de la vocalisation des néo-tifinagh», La lettre du RILB, Répertoire des Inscriptions Libyco-Berbères, 20, EPHE-Ive Section, Paris: $5-10$.

Aghali-ZaKara, M. y Drouin, J. (2007): Inscriptions rupestres libyco-berbères Sahel Nigéro-Malien, Droz, Ginevra.

Aghali-Zakara, M. y Drouin, J. (2009): «Station du Bonhomme et les messages écrits», La lettre du RILB, Répertoire des Inscriptions Libyco-Berbères, 15, EPHEIVe Section, Paris: 2-10.

Ait Ali YAHIA, S. (2012): Étude comparative entre les stèles à inscriptions libyques de la 
Berbèrie Centrale (Algérie) et de la Berbèrie Occidentale (Maroc) (Thèse de doctorat), Université Mouloud Mammeri, Tizi Ouzou.

Álvarez Delgado, J. (1964): Inscripciones líbicas de Canarias. Ensayo de interpretación líbica, Universidad de La Laguna, La Laguna.

Basset, A. (1952): La Langue Berbère, Oxford University Press, London-New YorkToronto.

BASSET, R. (1885): Notes de lexicographie berbère, Quatrième série: Vocabulaire du Touat et du Gourara, Argot du Mzab, dialectes des Touaregs Aouelimmiden, Imprimerie Nationale, Paris.

Belmonte Avilés, J. A. et al. (2019): «Calendario, signo y símbolo: tres claves para una aproximación al poblamiento del archipiélago canario», en Un periplo docente e investigador. Estudios en homenaje al profesor Antonio Tejera Gaspar, Universidad de La Laguna: 207-232.

BÉNABOU, M. (1976): La résistance africaine à la romanisation, Maspero, Paris.

CAlvet, L.J. (1996): Historia de la escritura, Paidós, Barcelona.

Cervelló Autuori, J. (2016): Escrituras, lengua y cultura en el Antiguo Egipto, Universitat Autònoma de Barcelona.

CAMPS, G. (1978): «Recherches sur les plus anciennes inscriptions libyques de l'Afrique du Nord et du Sahara», Bulletin archéologique du Comité des Travaux Historiques et Scientifiques, 10-11: 143-166.

CAMPS, G. (1990): «Qui sont les Dii Mauri ?», Antiquités africaines, 26: 131-153.

CAMPs, G. (1999): «Gudâla/Guezula», en Encyclopédie berbère, 21, Edisud, Aixen-Provence [en línea], publicado el 1 de junio de 2011, URL: http:// encyclopedieberbere.revue.org/1788 [Consulta: 01/05/2019].

Cantineau, J. (1960): Études de linguistique arabe, Klincksieck, Paris.

CAsajus, D. (2015): L'alphabet touareg. Histoire d'un vieil alphabet africain, CNRS, Paris.

Снавот, J.-B. (1939): «Sur quelques signes de l'alphabet libyque», Journal asiatique: ou recueil de mémoires d'extraits et de notices relatifs à l'histoire, à la philosophie, aux sciences, à la littérature et aux langues des peuples orientaux, CCXXXI, JeanMarie Durand, Paris: 117-124.

Cнавот, J.-B. (1940): Recueil des Inscriptions Libyques, Imprimerie Nationale, Paris. CHADwick, J. (1962 [1958]): El enigma micénico, Taurus, Madrid.

Chaker, S. (1985a): «Onomastique berbère ancienne (Antiquité/Moyen Age): rupture et continuité», Bulletin archéologique du CTHS, serie 9, fascículo 19B: 483-497.

ChaKer, S. (1985b): «Adjectif», en Encyclopédie berbère, 2, Edisud, Aix-en-Provence [en internet], publicado el 1 de diciembre de 2012, https://journals. openedition.org/encyclopedieberbere/857 [Consulta: 01/05/2019].

CHAKer, S. (1888 [1986]): «Terminologie libyque des titres et fonctions», Annali del'Istituto Universitario Orientale di Napoli, 46/4: 541-562.

Champollion, F. (1822): Lettre à M. Dacier relative à l'alphabet des hiéroglyphes phonétiques, Imprimerie de Firmin Didot, Paris.

C.H.E.C. (1988): «Nuevos grabados alfabetiformes aborígenes», La Provincia, 08/11/1988. 
Colin, F. (1996): Les Libyens en Egypte (xve siècle a. C. -IIe siècle p. C). Onomastique et histoire, vol. I- II, Université Libre de Bruxelles.

Colin, F. (1999): «Le vieux libyques dans les sources égyptiennes du Nouvel Empire à l'époque roman», Bulletin archéologique du Comité des travaux historiques et scientifiques, nouvel série, Afrique du Nord, fasc. 25: 13-18.

Cuenca SANABria, J. (1996): «Las manifestaciones rupestres de Gran Canaria», en A. Beltrán (ed.), Manifestaciones rupestres de las Islas Canarias, Dirección General de Patrimonio Histórico, Santa Cruz de Tenerife: 133-22.

Cunchillos, J.L.; Zamora, J.A. (1997): Gramática fenicia elemental, Consejo Superior de Investigaciones Científicas, Madrid.

DALLET, J.-M. (1982): Dictionnaire kabyle-français, SELAF, Paris.

DelHeure, J. (1987): Dictionnaire Ouargli-Français, SELAF, Paris.

Demougeot, É. (1960): «Le chameau et l'Afrique du Nord romaine», Annales. Economies, sociétés, civilisations, 15, 2: 209-247.

Desanges, J. (1962): Catalogue des tribus africaines de l'antiquité classique à l'ouest du Nil, Université de Dakar, Faculté des Lettres et Sciences Humaines, Dakar.

Drouin, J. (2007): «Le signe $\vdots$ / h/ est-il une mater lectionis dans les inscriptions Libyco-Berbères ?», La lettre du RILB, Répertoire des Inscriptions LibyqueBerbères, 15, EPHE- Ive Section, Paris: 6-7.

Drouin, J. (2011): «Fonctions et usages des signes composites, les tifinagh aqqânnin», La Lettre du RILB, Répertoire des Inscriptions Libyco-Berbères, 17, EPHE- IVe Section, Paris: 9-12.

Euzennat, M. (1985): «L'olivier et le limes», Bulletin archéologique du CTHS, serie 9, fascículo 19B: 161-171.

Ewague, A. et al. (2016): "Laghchiwat, nouveau site rupestre au sud d'Es Smara (Sahara marocain)», Lettre internationale d'informations sur l'art rupestre,75: 5-11.

FARrujia de LA Rosa, A. J. et al. (2009): «Las escrituras líbico-bereberes y latinocanaria en la secuenciación del poblamiento de las Islas Canarias», El Museo Canario, 64: 9-50.

FÉvrIER, J. G. (1956): «Que savons-nous du libyque ?», Revue Africaine. Centenaire de la Société Historique Algérienne 1856-1956, Jourdan, Alger: 263-273.

FoucAuld, Ch. y BASSET, A. (1940): Dictionnaire abrégé touareg-français de noms propres: dialecte de l'Ahaggar, Larose, Paris.

GALAND, L. (1960): «Berbères», en Encyclopédie de l'Islam, I, A-B, Brill, Leiden: 12081222.

GALAND, L. (1966): «Inscriptions libyques», en Inscriptions Antiques du Maroc, CNRS, Paris: 1-80.

GALAND, L. (1973a): «L'inscription libyco-berbère de Loma de Aasli (Seguiet elHamra)», Almogaren, 4: 81-90.

Galand, L. (1973b): «L'alphabet libyque de Dougga», Revue des mondes musulmans et de la Méditerranée, 13-14: 361-368.

GALAND, L. (1976): «Inscriptions berbères du Sahara occidental», Almogaren, 7: 7579.

Galand, L. (2002): Études de linguistique berbère, Peeters, Leuven-Paris. 
GAlAnd-Pernet, P. y GALAND, L. (1995): «Notes d'onomastique et de vocabulaire berbères», L'homme méditerranéen. Mélanges offerts à Gabriel Camps, Publications de l'Université de Provence. Aix-en-Provence: 265-270.

García Navarro et alii (2004): «Nueva estación de grabados rupestres localizada en la necrópolis de Arteara, San Bartolomé de Tirajana. Gran Canaria», Tabona: Revista de Prehistoria y de Arqueología, 12: 119-136.

GeLb, I. J. (1976 [1952]): Historia de la escritura, Alianza, Madrid.

GHAKI, M. (2000): «Stèles libyques et néopuniques de Tunisie», en L'Africa romana: lo spazio marittimo del Mediterraneo occidentales: atti del 14. Convegno di studio, 7-10 dicembre 2000, Sassari, Carocci, Roma: 1661-1678.

GHAKI, M. (2011): «Une nouvelle inscription libyque officielle à Dougga», en Parcours Berbères Mélanges offerts à P. Galand-Pernet et L. Galand pour le 90 eme anniversaire, Berber Studies, 33, Rüdiger Köppe, Köln: 1-5.

Gsell, S. (1927): Histoire ancienne de l'Afrique du Nord, Libraire Hachette, Paris.

Halévy, J. (1874): «Essai d'épigraphie libyque», Journal asiatique ou Recueil de mémoires d'extraits et de notices, serie 7, tomo IV, Imprimerie Nationale, Paris.

Heath, J. (2005): A Grammar of Tamashek (Tuareg of Mali), Part 1, Mouton de Gruyter, Berlin - New York.

Jongeling, K. (1984): Names in Neo-Punic inscriptions, University of Groningen.

JoNGELING, K. (1994): North-African names from Latin sources, Research School CNWS, Leiden.

JudAs, A.-C. (1863): Sur l'écriture et la langue berbères dans l'antiquité et de nos jours, Imprimerie de Pillet fils aîné, Paris.

Haddadou, M. A. (2006): Dictionnaire des racines berbères communes, HautCommissariat à l'Amazighité, Alger.

KHAYARI, A. el (2004): «Considérations sur l'épigraphie libyque du Maroc», en M.H. FANTAR y A. SirAJ (eds.), Débuts de l'écriture au Maghreb, Fondation du roi Abdul-Aziz Al-Saoud pour les Études Islamiques et les Sciences Humaines, Casablanca: 91-113.

Kossmann, M. (1999): Essai sur la phonologie du proto-berbère, Rüdiger Köppe, Köln. Kossmann, M. (2020): «Sibilants in Libyco-Berber», Journal of the American Oriental Society, 140 (4): 875-888.

Laoust, E. (1921): Cours de Berbère Marocain, Dialectes du Sous du Haut et de l'AntiAtlas, Challamel, Paris.

Letourneux, A. H. (1880 [1878]): «Du déchiffrement des inscriptions libycoberbères», en Atti del IV Congresso Internazionale degli Orientalisti, 1, Firenze: 57-75.

Lhote, H. (1975): Hacia el descubrimiento de los frescos del Tasili. La pintura prehistórica del Sahara, Ediciones Destino, Barcelona.

Lhote, H. (1982): Les chars rupestres sahariens. Des Syrtes au Niger par les pays des Garamantes et des Atlantes, Hespérides, Toulouse.

Lux, C. (2013): Le tetserret, langue berbère du Niger. Berber Studies, Rüdiger Köppe, Köln.

Marcy, G. (1932): «La Pierre écrite d" Ain Jema'a», Bulletin de la Société de préhistoire du Maroc, 6, Société de préhistoire du Maroc, Casablanca: 14-22. 
Marcy, G. (1936): Les inscriptions bilingues de l'Afrique du Nord, Imprimerie Nationale, Paris.

MARTín RodrígueZ et alii (2008): «Nuevas investigaciones en torno a los grabados rupestres del Barranco de Balos (Agüimes, Gran Canaria)», Tabona: Revista de Prehistoria y de Arqueología, 16: 193-218.

Martinet, A. (1983): «La palatalización "espontánea" de G en árabe"», Evolución de las lenguas y reconstrucción, Gredos, Madrid: 235-249.

Mora Aguiar, I. (2017): «Historia de los alfabetos líbico-bereberes a través del

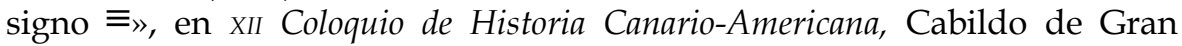
Canaria, Las Palmas de Gran Canaria: 1-17.

Mora Aguiar, I. (2021): «La dispersión de la escritura líbico-bereber desde Numidia hasta Canarias», en N. Moncunill y M. Ramírez-SÁnchez (eds.), Aprender la escritura, olvidar la escritura: Nuevas perspectivas sobre la historia de la escritura en el Occidente romano, Universidad del País Vasco, Vitoria-Gasteiz: 37-62.

NaïT-Zerrad, K. (2002a): «Les préfixes expressifs en berbère», Articles de linguistique berbère, Mémorial Werner Vycichl, L'Harmattan, Paris: 349-372.

NAÏT-ZerRAD, K. (2002b): Dictionnaire des racines berbères (formes attestées), III, Peeters, Paris-Louvain.

NAÏT-ZeRrad, K. (2011): Mémento grammatical et orthographique de berbère. KabyleChleuh-Rifain, L'Harmattan, Paris.

Perera Betancort, M.A.; Jiménez GonZÁlez, J.J. (2020): «Manifestaciones rupestres y estructuras arqueológicas de Montaña Jaifa, Fuerteventura», en XXIII Coloquio de Historia Canario-Americana (2018), Cabildo de Gran Canaria, Las Palmas de Gran Canaria: 1-17.

Pichler, W. (2003): Las inscripciones rupestres de Fuerteventura, Cabildo de Fuerteventura, Puerto del Rosario.

PICHLER, W. (2008): «The Libyco-Berber inscriptions of Foum Chenna/Morocco», Sahara, 19, Pyramids, Segrate: 184-191.

Poyto, R.; Musso, J.-C. (2001 [1969]): «Ifira», en Encyclopédie berbère, 24, Ida Issamadanen, Edisud, Aix-en-Provence: 3643-3644.

Prasse, K.-G. (1972): Manuel de grammaire touarègue (tăhăghart), I-III, Forlag, Copenhague.

Prasse, K.-G. (1974): Manuel de Grammaire Touarègue (tăhăghart), IV-v, Forlag, Copenhague.

Provotelle, P. (1911): Étude sur la Tamazir't ou Zénatia de Qalaât Es-Sened (Tunisie), Ernest Leroux, Paris.

Putten, M. van (2014): A Grammar of Awjila (Libya). Berber Studies, Rüdiger Köppe, Köln.

Putten, M. van (2017): «Are Libyco-Berber horizontal $\underline{T}$ and vertical $H$ the same sign?», en L. Nehmé y AL- A. Jallad (eds.), To the Madbar and Back AgainStudies in the languages, Archaeology, and Cultures of Arabia Dedicated to Michael C.A. Macdonald, Brill, Leiden: 346-357.

Ramírez Sánchez, M. (2010): "Tres décadas de debate sobre las supuestas inscripciones latinas de Lanzarote y Fuerteventura», en VII Congreso de Patrimonio Histórico: Inscripciones rupestres y poblamiento del Archipiélago 
canario, Cabildo insular de Lanzarote, Arrecife: 393-417.

Rodríguez, A.; Pichler, W. (2007): Libyco-Berber inscriptions database, Institutum

Canarium, Wien, [en internet], URL: http:/ / www.institutum-canarium.org/ lbi-project/ [Consulta: 01/05/2019].

Rössler, O. (1958): «Die Sprache Numidiens», Sybaris: Festschrift Hans Krahe,

Harrassowitz, Wiesbaden: 94-120.

SAUlCY, F. DE (1843): «Sur l'inscription bilingue de Thougga», Journal asiatique, 4 (1): 85-126.

SAVAGE, A. (2012): «Structure syllabique de la langue touarègue nouvel éclairage sur les voyelles schwa et 'a bref'», Études et Documents Berbères, 31: 95-135.

SPRINGER BUNK, R.A. (1994): Las inscripciones líbico-bereberes de las Islas Canarias, tesis doctoral inédita, Universidad de La Laguna

SPRINGER BunK, R.A. (1996): «Las inscripciones alfabéticas líbico-bereberes del archipiélago canario», en A. BELTRÁN (ed.), Manifestaciones rupestres de las Islas Canarias, Dirección General de Patrimonio Histórico, Santa Cruz de Tenerife: 393-417.

Springer BunK, R.A. (2001): Origen y uso de la escritura líbico-bereber en Canarias, Centro de la Cultura Popular Canaria, La Laguna.

SPRINGER BUNK, R.A. (2017): «La escritura líbico-bereber de las Islas Canarias: ¿uno o varios alfabetos?», Tabona, revista de Prehistoria y Arqueología, 21: 29-46.

SPRINGER BunK, R. A. (2019): «El alfabeto líbico-bereber canario: la distribución geográfica de los signos en el Norte de África y Sáhara», Vegueta: anuario de la Facultad de Geografía e Historia, 19: 759-772.

SPRINGER BunK, R.A. (en prensa): «Características de los yacimientos de grabados rupestres canarios y los signos empleados en las inscripciones alfabéticas», Études et Documents Berbères.

SouAG, L. (2017): «La diffusion en berbère: Réconcilier les modèles», Diffusion: Implantation, Affinités, Convergence, 24, Peeter, Paris: 88-107.

TAÏFI, M. (1991): Dictionnaire tamazight-francais (parlers du Maroc central), L'Harmattan-Awal, Paris.

TAINE-CHeiKH, C. (1999): «Le zénaga de Mauritanie à la lumière du berbère commun», en M. LAmberti y A. Tonelli (eds.): Afroasiatica Tergestina, Hal, Trieste: 299-324.

Trousset, P. (1982): «Le franchissement des chotts du Sud tunisien dans l'Antiquité», Antiquités africaines, 18, CNRS, Paris: 45-69.

Ulbrich, H.-J. (1996): «Neue Felsbildstationen auf der Kanareninsel Lanzarote (II)». Almogaren, 27: 285-358.

Velasco VÁzQUEZ, J. et al. (2020): «Poblamiento, colonización y primera historia de Canarias: C14 como paradigma», Anuario de Estudios Atlánticos, 66: 1-24.

Vycichl, W. (1955): «Les gétules de la Mauritanie», Bulletin de l'Institut français d'Afrique noire, Série B, Sciences humaines, 17: 163-167.

YoyotTe, J. (1958): «Anthroponymes d'origine libyenne dans les documents égyptiens», Comptes rendus du Groupe Linguistique d'Études Chamito-Sémitiques (GLECS), Geuther, Paris: 22-24. 